Article

\title{
Recent Declines in Warming and Vegetation Greening Trends over Pan-Arctic Tundra
}

\author{
Uma S. Bhatt ${ }^{1, *}$, Donald A. Walker ${ }^{2}$, Martha K. Raynolds ${ }^{2}$, Peter A. Bieniek ${ }^{1,3}$, \\ Howard E. Epstein ${ }^{4}$, Josefino C. Comiso ${ }^{5}$, Jorge E. Pinzon ${ }^{6}$, Compton J. Tucker ${ }^{6}$ \\ and Igor V. Polyakov ${ }^{3}$
}

1 Geophysical Institute, Department of Atmospheric Sciences, College of Natural Science and Mathematics, University of Alaska Fairbanks, 903 Koyukuk Dr., Fairbanks, AK 99775, USA; E-Mail: pbieniek@alaska.edu

2 Institute of Arctic Biology, Department of Biology and Wildlife, College of Natural Science and Mathematics, University of Alaska, Fairbanks, P.O. Box 757000, Fairbanks, AK 99775, USA; E-Mails: dawalker@alaska.edu (D.A.W.); mkraynolds@alaska.edu (M.K.R.)

3 International Arctic Research Center, Department of Atmospheric Sciences, College of Natural Science and Mathematics, 930 Koyukuk Dr., Fairbanks, AK 99775, USA;

E-Mail: igor@iarc.uaf.edu

4 Department of Environmental Sciences, University of Virginia, 291 McCormick Rd., Charlottesville, VA 22904, USA; E-Mail: hee2b@virginia.edu

5 Cryospheric Sciences Branch, NASA Goddard Space Flight Center, Code 614.1, Greenbelt, MD 20771, USA; E-Mail: josefino.c.comiso@nasa.gov

6 Biospheric Science Branch, NASA Goddard Space Flight Center, Code 614.1, Greenbelt, MD 20771, USA; E-Mails: jorge.e.pinzon@nasa.gov (J.E.P.); compton.j.tucker@nasa.gov (C.J.T.)

* Author to whom correspondence should be addressed; E-Mail: usbhatt@alaska.edu; Tel.: +1-907-474-2662; Fax: +1-907-474-2473.

Received: 15 June 2013; in revised form: 17 July 2013 / Accepted: 19 August 2013 / Published: 29 August 2013

Abstract: Vegetation productivity trends for the Arctic tundra are updated for the
1982-2011 period and examined in the context of land surface temperatures and coastal
sea ice. Understanding mechanistic links between vegetation and climate parameters
contributes to model advancements that are necessary for improving climate projections.
This study employs remote sensing data: Global Inventory Modeling and Mapping Studies
(GIMMS) Maximum Normalized Difference Vegetation Index (MaxNDVI), Special
Sensor Microwave Imager (SSM/I) sea-ice concentrations, and Advanced Very High 
Resolution Radiometer (AVHRR) radiometric surface temperatures. Spring sea ice is declining everywhere except in the Bering Sea, while summer open water area is increasing throughout the Arctic. Summer Warmth Index (SWI-sum of degree months above freezing) trends from 1982 to 2011 are positive around Beringia but are negative over Eurasia from the Barents to the Laptev Seas and in parts of northern Canada. Eastern North America continues to show increased summer warmth and a corresponding steady increase in MaxNDVI. Positive MaxNDVI trends from 1982 to 2011 are generally weaker compared to trends from 1982-2008. So to better understand the changing trends, break points in the time series were quantified using the Breakfit algorithm. The most notable break points identify declines in SWI since 2003 in Eurasia and 1998 in Western North America. The Time Integrated NDVI (TI-NDVI, sum of the biweekly growing season values of MaxNDVI) has declined since 2005 in Eurasia, consistent with SWI declines. Summer (June-August) sea level pressure (slp) averages from 1999-2011 were compared to those from 1982-1998 to reveal higher slp over Greenland and the western Arctic and generally lower pressure over the continental Arctic in the recent period. This suggests that the large-scale circulation is likely a key contributor to the cooler temperatures over Eurasia through increased summer cloud cover and warming in Eastern North America from more cloud-free skies.

Keywords: AVHRR NDVI3g; tundra vegetation; climate variability; sea ice; Arctic

\section{Background and Rationale}

The remotely sensed Normalized Difference Vegetation Index (NDVI) documents that arctic tundra vegetation greenness has overall increased [1-8] during the satellite record and is linked to increased vegetation productivity as measured by above-ground biomass [9-12]. This pan-Arctic tundra vegetation greening is associated with increases in summer warmth $[2,10]$ that are, in large-part, driven by summer sea-ice retreat along arctic coasts based on observational [13-16] and modeling studies [17-19]. Impacts of sea-ice decline on tundra vegetation productivity have been shown to weaken with distance from the coast in Eurasia [16] and to increase tundra-fire frequency in northern Alaska [20]. Since $80 \%$ of arctic tundra is within $100-\mathrm{km}$ of the coast, the link between this coastal vegetation biome and sea ice is not unexpected [21].

The more regional view reveals large heterogeneity in NDVI and land-surface warming trends, similar to the regional manifestations of anthropogenic climate change. Most tundra vegetation is summer-temperature limited so summer warming will generally enhance productivity, however, other local factors are also important such as glacial history [22], winter temperatures, snow cover, precipitation, soil moisture [23], and land-use history [24,25]. These factors are very important for understanding the very heterogeneous signals that are coming from global assessments of plot-scale response to experimental warming [23].

Ground-based studies support remote sensing NDVI trends, by documenting increased tundra biomass $[23,26,27]$ and enhanced shrub cover, particularly in riparian areas [28-32]. Field data from 
the North American Arctic Transect (NAAT) and Eurasian Arctic Transect (EAT) were examined in conjunction with remotely sensed NDVI data by Raynolds et al. [11]. They showed that the amount of aboveground biomass in the Arctic is correlated with remotely sensed NDVI, and more importantly the relationship is similar for both transects, despite having substantially different mean biomass values.

It is important to understand how arctic vegetation is changing because of subsequent implications for the global carbon budget, surface energy budget and large-scale climate. The arctic tundra is currently considered a carbon sink though that could change as warming air temperatures due to declining sea ice induce the thawing of frozen soils and carbon release [33]. Zhang et al. [34] imposed arctic-vegetation greening (reduced albedo) in a general circulation model (GCM) north of $60^{\circ} \mathrm{N}$ and the model response included surface warming, reduced atmospheric stability and enhanced convection. In another GCM study, the response to imposed arctic-vegetation greening showed a warming of the tundra surface through albedo reductions and a large-scale atmospheric response favoring the negative phase of the Arctic Oscillation (high sea level pressure in the Arctic and lower pressure in the midlatitudes) [35]. An anomalously high sea level pressure over the Arctic can decrease sea-ice area through Ekman transport as shown in an observational study of Ogi et al. [36], suggesting a greening of the Arctic could further reduce sea-ice cover through a positive feedback. Climate mechanisms of how tundra vegetation changes influence the carbon budget and the atmosphere-ocean circulations are important to elucidate and include in GCMs, in order to better anticipate future climate states.

Recent updates to our past work suggest that the warming and greening trends over pan-Arctic tundra have slowed down [37], and in this paper we document the changing trends of the GIMMS NDVI3g over arctic tundra. Additionally, we examine the trends in the context of large-scale climate anomalies and longer-term variability in the Arctic.

\section{Study Objectives and Area}

The study will first present an update of our previous analysis from Bhatt et al. [14] on the pan-Arctic scale and then discuss differences between North America and Eurasia in the context of climate variability. More specifically, this study will address the following questions:

- What are the current (1982-2011) pan-Arctic tundra vegetation trends and those of their associated climate parameters? How do these trends compare to those over the 1982-2008 period? How do these trends compare to those based on new sensor data over the 2000-2011 period?

- What is the regional characterization of these trends? How different are MaxNDVI changes in North America and Eurasia [5,38]? Are there distinct break points in the time series of SWI, MaxNDVI, and TI-NDVI? How do these trends and variations compare to the larger spatial and longer time scale climate? Could large-scale climate variability impact arctic air temperatures in summer?

This study will focus on the non-alpine tundra of the Arctic (Figure 1). The Arctic tundra zone is defined according to the Circumpolar Arctic Vegetation Map [21], with a southern boundary delineated by the arctic tree line. The arctic zone is subdivided into bioclimate subzones [21] based on the available summer warmth and dominant vegetation, with Subzone A being the coolest and E being the warmest. The tundra is a maritime biome that is kept cool by the presence of coastal sea ice during 
at least part of growing season. Approximately $80 \%$ of arctic tundra with elevations less than $300 \mathrm{~m}$ is within $100-\mathrm{km}$ of the coastline. Sea ice is closely linked to the available summer warmth and ice area (greater than $50 \%$ concentration) at the beginning of May (light blue color over ocean in Figure 1) is reduced by the end of the growing season in late August (white color over ocean in Figure 1). Even in late August Subzone A and much of Subzone B are in close proximity of the cooling effects of sea ice. The starting point of this paper will be a pan-Arctic analysis and will be followed by an analysis of regional variability in Eurasia, Western North America and Eastern North America. The final results section will examine climate data from station measurements and reanalysis in the context of the remote-sensing results.

Figure 1. This map identifies oceanic and terrestrial regions (solid grey lines) of the Arctic used in the analysis. Colors over land identify the bioclimate subzones A-E of the Circumpolar Arctic Vegetation Map (CAVM) of Walker et al. [21]. The climatological (1982-2012 average) sea-ice edge indicating values at the 50\% concentration level and higher are shown in light green for early May and white for late August. Regional time series are constructed for Western North America (E. Bering, E. Chukchi, Beaufort, S. Canadian Archipelago Straits, Foxe Basin, and Hudson Bay), Eastern North America (N. Canadian Archipelago Straits, Baffin Bay, Hudson Strait, Davis Strait, Denmark Strait, and Greenland), and Eurasia (N. Barents, S. Barents, W. Kara, E. Kara, Laptev, E. Siberian, W. Chukchi, W. Bering). A red star identifies Eastern North America regions.

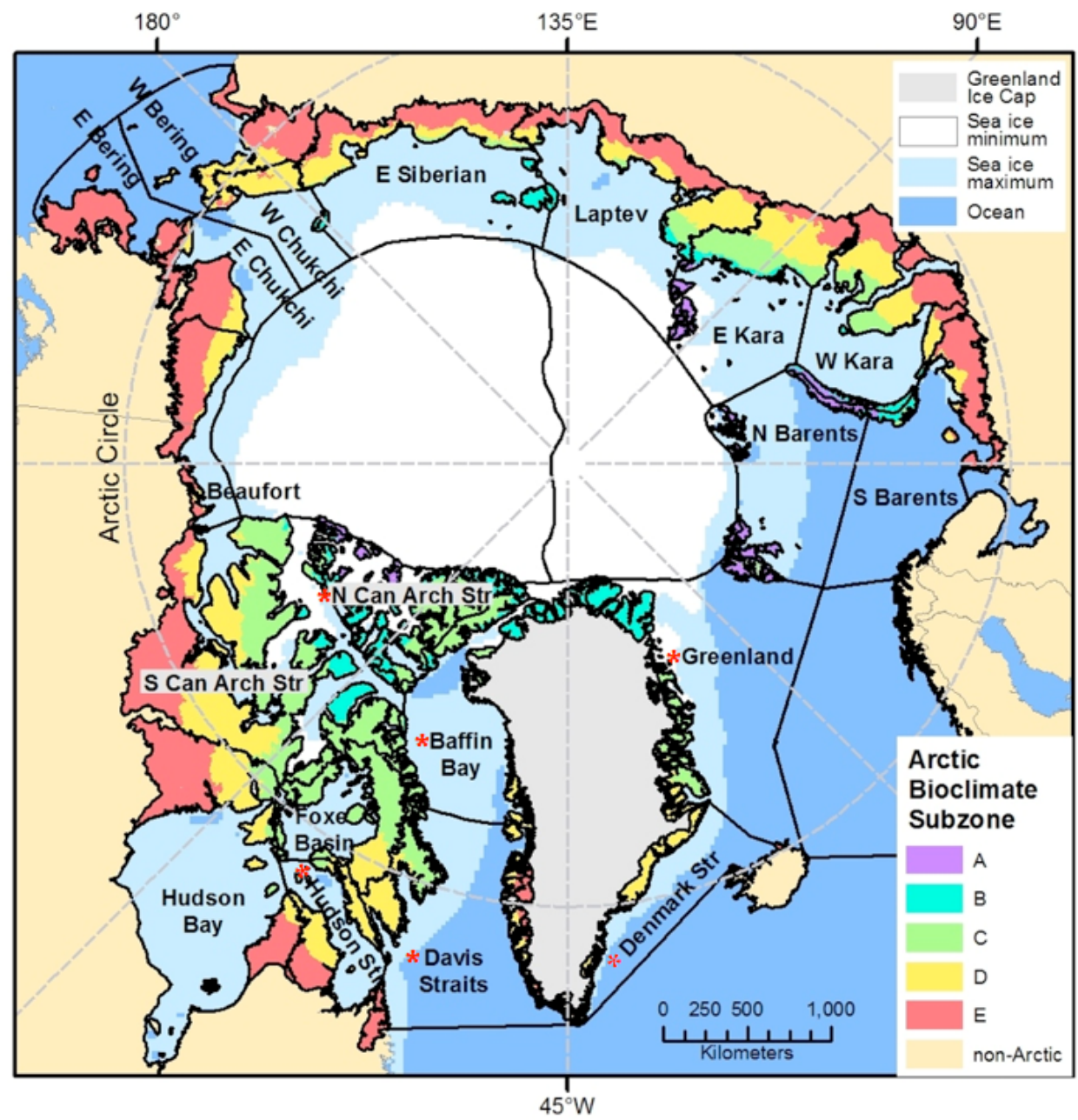




\section{Approach and Methods}

\subsection{Remote Sensing Data}

Special Sensor Microwave Imager (SSM/I) sea-ice concentrations [39] and Advanced Very High Resolution Radiometer (AVHRR) radiometric surface temperature are investigated over the 1982-2011 period. The term sea-ice concentration is used in this publication to describe sea-ice area in units of percent area covered. The remotely-sensed surface temperature data have been corrected through effective cloud-masking techniques and calibration through the utilization of in situ surface-temperature data. Surface temperatures from the Surface Heat Budget in the Arctic (SHEBA) experiment conducted in the central Arctic from October 1997 through September 1998 and 2-m air temperatures from meteorological stations were used to calibrate the AVHRR data. Details of this procedure can be found in Comiso et al. [40]. The Summer Warmth Index (SWI) was calculated as the sum of average May to September monthly surface temperatures above freezing at each pixel and is in units of ${ }^{\circ} \mathrm{C}$ months.

Remotely-sensed 8-km resolution NASA GIMMS (Global Inventory Modeling and Mapping Studies) [41] bi-weekly maximum NDVI data from 1982 to 2011 are derived from AVHRR sensors that were flown on NOAA-7 through NOAA-18 satellites. The NDVI3g product corrected discontinuities in the GIMMS NDVI north of $72^{\circ} \mathrm{N}$ and permitted the first comprehensive analysis of NDVI trends in the High Arctic [14]. The new GIMMS3g data set uses Sea-viewing Wide Field-ofview Sensor (SeaWIFS) for calibrating between sensors. The old GIMMS series used Systeme Pour I'Observation de la Terre (SPOT) data, which only had coverage to $72^{\circ} \mathrm{N}$ and created an artificial discontinuity at that latitude. The AVHRR time series was compared with Moderate Resolution Imaging Spectroradiometer (MODIS) data, which samples narrower bands of wavelengths. Compared to AVHRR, MODIS NDVI is based on spectral bands that are specifically designed for vegetation monitoring and include state-of-the-art navigation, atmospheric correction, reduced geometric distortions and improved radiometric sensitivity [42]. The AHVRR data for the period of overlapping coverage show the same trends and variability as the MODIS data, validating the accuracy and consistency of the AVHRR time series. This study used approximately $12-\mathrm{km}$ resolution NDVI data to more closely match the grids used for sea ice and surface temperature in this study. The maximum NDVI (MaxNDVI) is the highest summer NDVI value, representing peak vegetation photosynthetic capacity, and serves as an indicator of tundra biomass [9,10]. The time-integrated NDVI (TI-NDVI) is the sum of biweekly values above 0.05 from May to September. TI-NDVI incorporates the length of the growing season and phenological variations and better represents gross primary production than MaxNDVI [43]. The TI-NDVI is better correlated with climate parameters since both are integrated measures of climate and vegetation, respectively during the growing season [14].

\subsection{Analysis Methods}

The Arctic Ocean was divided into sub-regions (Figure 1) modified from the Arctic Atlas of Treshnikov [44], and the adjacent land divisions approximately follow the floristic provinces of the Circumpolar Arctic Vegetation Map [21]. These subdivisions have been further divided since Bhatt et al. [14] to better reflect regional variations. For example, the Canadian Archipelago and the Barents Sea have been divided into northern and southern sub-regions to reduce the heterogeneity 
within these regions. For simplicity, both land and adjacent ocean areas will be identified by the name of the corresponding sea in this paper. The analysis employs time series averaged over oceanic regions within $100-\mathrm{km}$ of the arctic coastline and over the full tundra domains identified in Figure 1. Time series of summer open water (OW), SWI, MaxNDVI and TI-NDVI were constructed by averaging over regions to construct Western North America (E. Bering, E. Chukchi, Beaufort, S. Canadian Archipelago Straits, Foxe Basin, and Hudson Bay), Eastern North America (N. Canadian Archipelago Straits, Baffin Bay, Hudson Strait, Davis Strait, Denmark Strait, and Greenland), and Eurasia (N. Barents, S. Barents, W. Kara, E. Kara, Laptev, E. Siberian, W. Chukchi, W. Bering). The justification for dividing North America is provided in the results section.

The timing of the mean 50\% ice concentration was most strongly correlated with SWI in the following summer and displayed high variability, so it was chosen as the base period for analysing the sea-ice data in the context of tundra vegetation. Sea-ice time series were constructed using ice concentration data averaged over a three-week period centered on the week when mean concentrations were $50 \%$, the timing of which varies regionally. Open water (OW) is constructed by summing up the weekly May through August open-water percentage (units are \% open water area within a pixel) and then dividing by the number of weeks to produce an average weekly OW amount for the summer. OW was calculated for May-June and July-August (not shown), and these values display very similar variations to the May-August OW and spring sea-ice time series.

The least squares fit method was used to determine the trends of sea ice, open water, MaxNDVI, TI-NDVI and SWI in the spatial presentation (Figures 2 and 3). Time series trends and associated break points (timing of trends change) are quantified using a parametric, nonlinear regression technique called "breakfit regression" developed by Mudelsee $[45,46]$. This model is a continuous function consisting of two linear parts that are joined at the break point. The break model is fitted to data using a weighted least-squares method with a brute-force search for the break point. Statistical uncertainties of the trend and break point are evaluated in this study using 2000 block bootstrap simulations, which preserves the distribution and serial dependence of the data over the length of a block. A measure of robust standard error is provided with the break-point calculations. Details of the methodology can be found in Mudelsee [45].

Correlations are calculated on linearly detrended time series among OW, TI-NDVI, and SWI over the full tundra domain and a 100-km coastal zone over the ocean for OW. Correlations between indices constructed for the 50-km land and ocean areas (not shown) are generally stronger than those for full tundra and 100-km ocean domain. This is expected since the dominance of ocean and land coupling is limited to a fairly narrow coastal region [16]. The statistical significance of trends was assessed using a two-tailed t-test at the 5 and 10 percent levels.

\section{Results and Discussion}

\subsection{Pan-Arctic Trends}

Updating our previous analysis [14,47] with the addition of three more years of data results in a noticeable impact on arctic trends of sea ice, SWI and the GIMMS NDVI3g (Figures 2 and 3). Figure 2 displays the trends in spring sea-ice concentration, SWI, summer open water, and MaxNDVI for the 
1982-2011 period, while Figure 3 is the difference between the trends in Figure 2 and those for the period 1982-2008.

Figure 2. Magnitude trends (1982-2011) for (a) spring sea-ice concentration (\%) (as represented by trends from the climatological 50\% sea-ice concentration level) and land-surface summer warmth index (SWI) $\left({ }^{\circ} \mathrm{C}\right.$ month), (b) summer (May-August) open water area (\%) and annual MaxNDVI (unitless). Trends were calculated using a least squares fit (regression) at each pixel. The SWI is the annual sum of the monthly mean temperatures $>0{ }^{\circ} \mathrm{C}$, derived from AVHRR thermal channels $3(3.5-3.9 \mu \mathrm{m})$, $4(10.3-11.3 \mu \mathrm{m})$ and $5(11.5-12.5 \mu \mathrm{m})$. The total trend magnitude (regression times 30 years) over the 1982-2011 period is presented.
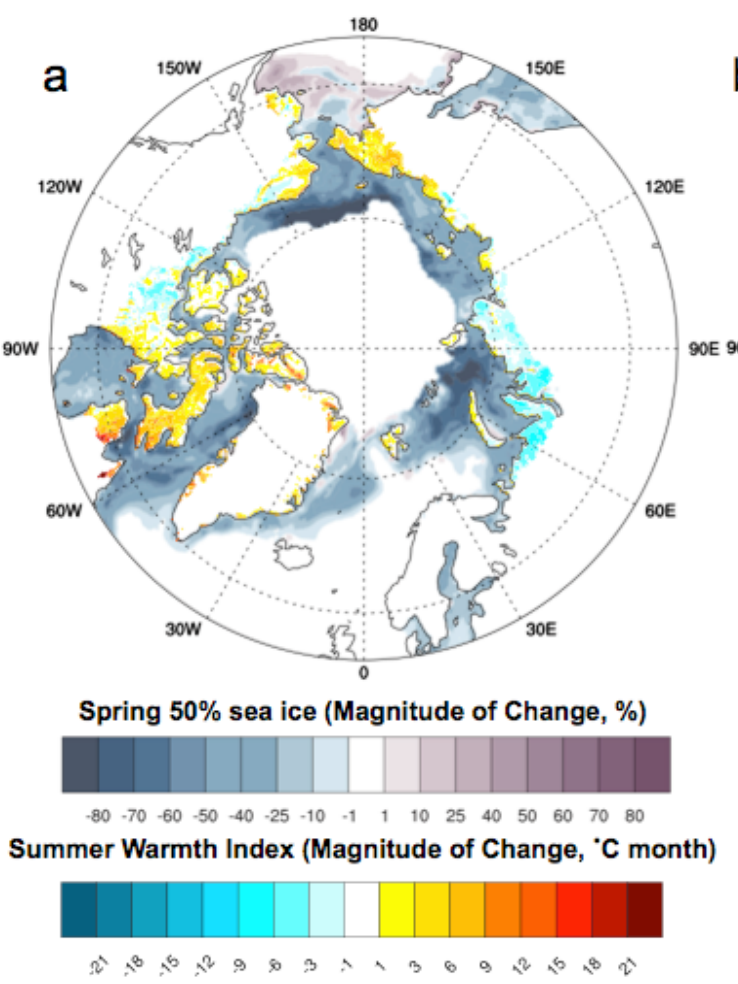

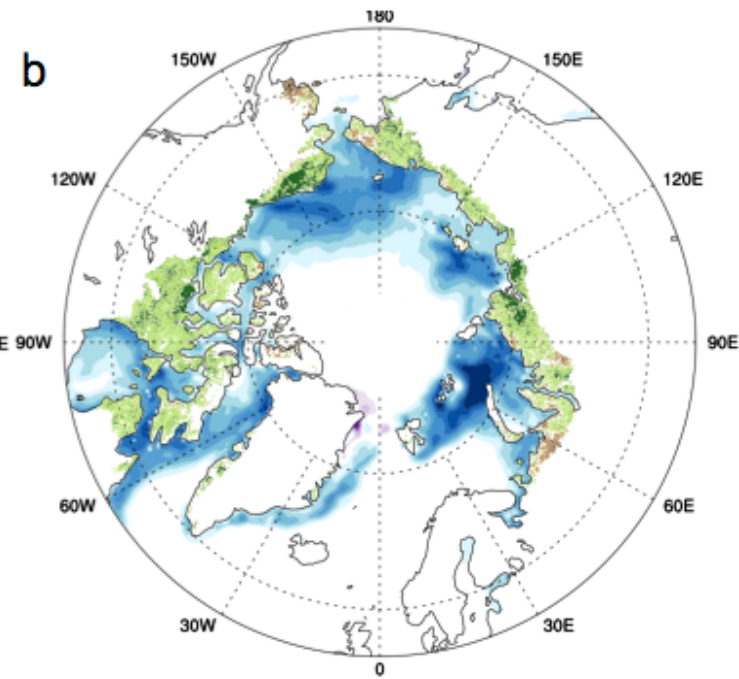

Summer Open Water (Magnitude of Change, \%)

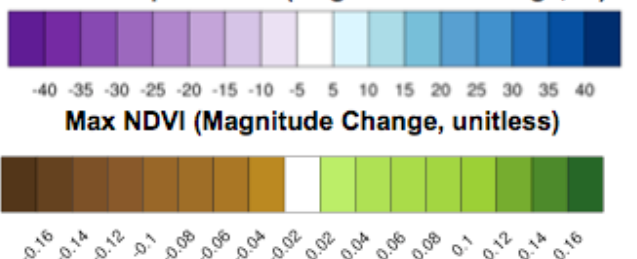

Spring sea-ice concentrations have continued to decline throughout the Arctic, especially in the Barents-Kara Seas, Baffin Bay and Beaufort-Chukchi Seas (Figure 2a) but have increased in the Bering Sea (Figure 3a). Sea ice has expanded in the Bering Sea due to a persistent anomalous northerly atmospheric circulation during recent winters [48], which advects ice farther south and enhances ice production. Both in situ and surface temperatures from AVHRR in the Bering Sea region have been showing a cooling trend over the last decade (see Figure 10g from Comiso 2012 [49]) as well as in winter (see Figures 6.2 and 6.3 from Comiso 2010 [50]). Both cooler temperatures and northerly winds are consistent with enhanced ice growth in the Bering Sea and a positive trend in ice extent. Figure 3a suggests the presence of spring sea ice is lengthening at its southern reaches but it is decreasing in the Arctic in recent years. 
Figure 3. This figure displays the change in trend using the latest data set at each pixel defined as 1982-2011 minus the 1982-2008 trend value. Panel (a) contains spring sea-ice concentration and summer warmth index, while panel (b) contains summer open water and MaxNDVI. Trends were calculated using a least squares fit (regression) at each pixel.

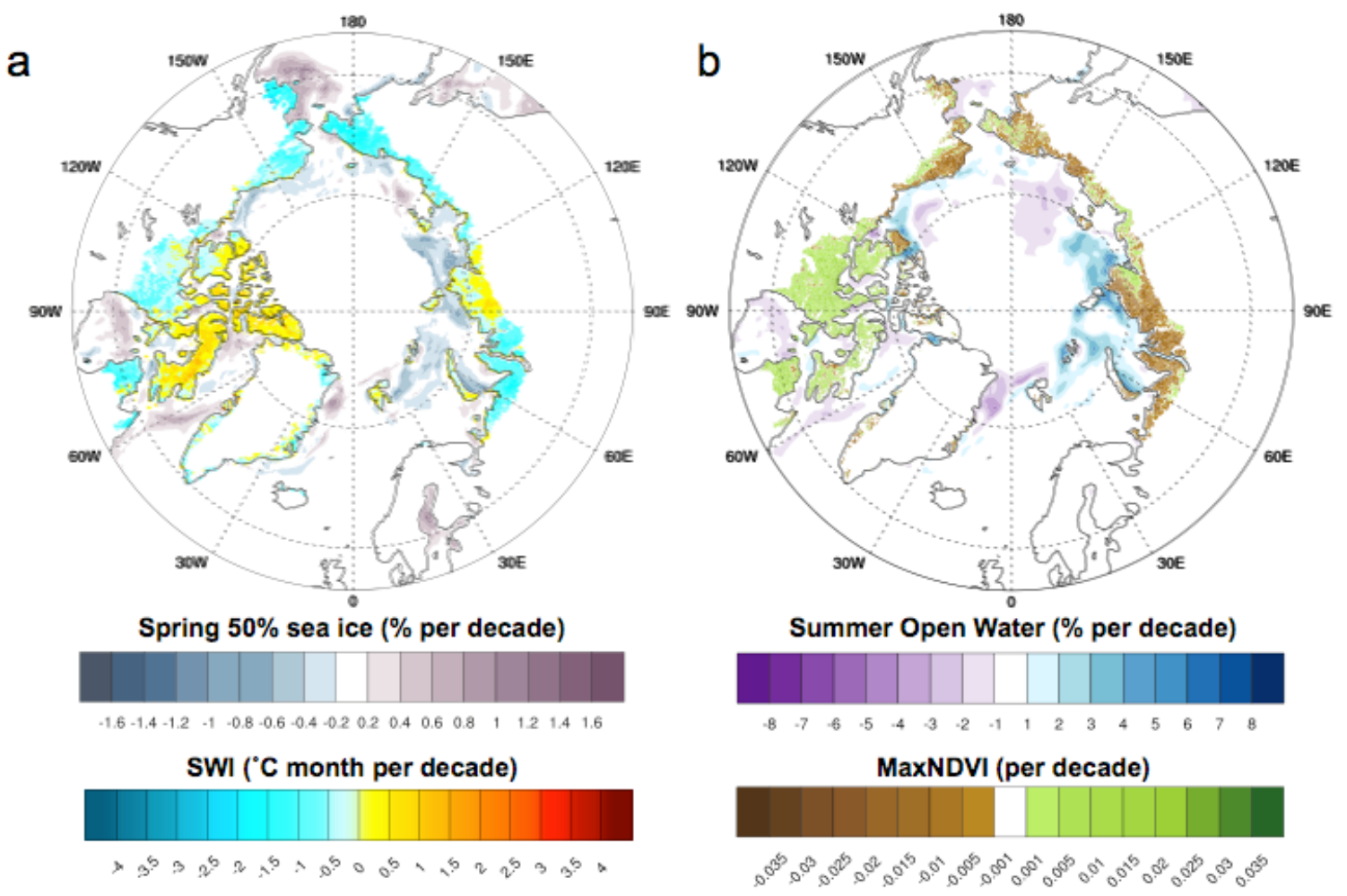

Summer open water (OW) has increased throughout the Arctic (Figure 2b) and while it displays similar variability with spring sea-ice concentrations (not shown), it provides an integrated view of the ocean during the growing season. Large increases of OW are evident throughout the Arctic except in the Bering and Greenland Seas. The open water is reduced in the Bering due to the longer presence of sea ice into the growing season and sea ice transport out of the Arctic ensures the presence of sea ice in the Greenland Sea in summer. The trend differences shown in Figure $3 b$ indicate a reduced positive trend of open water along Greenland, and offshore areas of the Beaufort and E. Siberian Sea. This is most likely associated with the presence of increasing amounts of mobile broken sea ice during summer. Weakened positive trends in open water in the E. Bering and Hudson Bay area are associated with reduced OW in spring. The positive trends of open water are strengthening in the Barents, Kara, and Laptev Seas. The OW trend is also becoming more positive along the Beaufort coast of northern Canada.

SWI trends have changed notably (compared with Figure 3b, [14]) over the Kara Sea and Canadian mainland tundra, where there is strong cooling in the latest analysis (Figure 2a). These differences are in part due to enhanced 2005-2008 (and later) temperature data, which were reprocessed for optimal accuracy, using data from NOAA-18/AVHRR as the baseline. Land-surface temperature data trends constructed for the 1982-2008 period using the updated AVHRR land-surface temperature data display stronger cooling over Eurasia (Appendix Figure A1a) than Bhatt et al. [14]. Surface air-temperature trends at meteorological stations (Appendix Figure A1b) display cooling in the Kara and Beaufort 
regions and compare qualitatively with the updated AVHRR trends though the trends tend to be more positive. The trend-difference plot for SWI (Figure 3b) indicates that trends are reduced (less positive or more negative) throughout the Arctic except for the Taimyr Peninsula $\left(98^{\circ} \mathrm{E}\right.$ longitude along the Laptev Sea), northern Canadian Archipelago, and Baffin Island (large island centered at $69^{\circ} \mathrm{N}, 72^{\circ} \mathrm{W}$ ).

Maximum-NDVI (MaxNDVI) trends signs have not changed with the inclusion of three additional years and still show declines in the West Kara region and southwest Alaska (Figure 2b). However, the 1982-2011 trends are less positive than the 1982-2008 trends (Figure 3b) over most of Eurasia, Alaska, southwest Greenland, and northern Canadian Archipelago. The trends are more positive over the southern Canadian and southern Alaskan tundra and along the Laptev Sea. The NDVI3g used in Bhatt et al. 2010 is an earlier version of the current version of NDVI3g data, so trend differences may arise from both three additional years of data and data reprocessing. The most striking difference from Bhatt et al. [14] is the NDVI decline in the high Canadian Arctic, which displayed strong positive trends in the previous analysis. The time integrated NDVI (TI-NDVI) trends over the 1982-2011 period are similar to those of MaxNDVI but have more pixels with negative trends over the Yamal $\left(70^{\circ} \mathrm{E}\right.$ longitude along the W. Kara Sea) and Taimyr Peninsulas. The TI-NDVI (not shown) is declining over the Seward Peninsula (E. Bering region), while MaxNDVI trends tend to be positive. The TI-NDVI presents an integrated measure of vegetation productivity and the longer presence of sea ice in spring may delay greenup and contribute to reduced TI-NDVI, while having little impact on MaxNDVI. TI-NDVI trends were positive throughout the Arctic in Bhatt et al. [14] with the exception of E. Bering and W. Chukchi (see their Figure 3d). TI-NDVI trends over the 1982-2011 period are generally positive except over E. Bering, W. Chukchi, and some pixels in the Kara Sea regions. A possible explanation of reduced TI-NDVI in the Barents and Kara Sea regions is related to enhanced snowfall resulting from increased storm penetration into this region [51-53]. Our analysis of GlobSnow, a data set supported by the European Space Agency and constructed by assimilating various in situ snow data, reanalysis products, and satellite data, suggests more snow water equivalent (SWE) during spring and fall in the E. Kara but not in the other regions. A recent paper by Brown and Derksen [54] suggests enhanced fall SWE is not consistent with temperature warming trends. Therefore, the potential snow mechanism has been elusive to substantiate and will require more research.

The updated analysis from 1982 to 2011 when compared with trends over the 1982-2008 period show striking differences as a reduction of positive SWI trends and a general weakening of the positive NDVI trends. SWI variations are quite large over the arctic tundra, and some of these fluctuations may be attributable to intrinsic climate variability in the Arctic, which can be quite large [55]. But as the sea ice declines and more open water is present, other processes may come into play that change the climate. Liu et al. [56] used satellite observations of sea ice and cloud cover for 2000-2012 and found that a $1 \%$ decrease in sea-ice concentration leads to a $0.36 \%-0.47 \%$ increase in cloud cover over the Arctic Ocean. Increased cloud cover during the summer acts to reduce surface temperatures. One possible interpretation is that sea ice is the initial trigger of the land-surface warming and once the open water area occurs more regularly, other climate feedbacks begin to operate that act to dampen the warming (e.g., Eurasia). There may be local climate feedbacks such as the strengthening of the sea breeze circulation on the Alaskan North Slope or large-scale feedbacks due to changes in the equator-to-pole temperature gradient. Earlier open water may cause increased cloudiness, or increased winter snowfall may increase standing water, both of which would slow down warming and NDVI 
increase. This idea is consistent with noted large positive warming and greening trends found in North America in the vicinity of Greenland, where the oldest, thickest ice is only recently melting in large amounts. These potential mechanisms require further research.

\subsection{Regional Trends and Variability}

Regional trends and correlations of open water, SWI, MaxNDVI and TI-NDVI viewed together for each region provide one method for categorizing regions that display similar patterns (Figure 4). Linearly detrended correlations are shown in Table 1 of OW with SWI, SWI with TI-NDVI, and OW with TI-NDVI. Stronger correlations are found between summer warmth and open water with TI-NDVI than MaxNDVI since these parameters are integrated over the growing season. Correlations quantify how well two time series vary together and are a separate measure from the trend in this case, since the data have been linearly detrended. In general, the trends and correlations are consistent with each other [14]. In other words, when SWI trends are positive so are TI-NDVI and OW trends, and these variables are all positively correlated with each other.

The regions where trends of open water, SWI, MaxNDVI and TI-NDVI are all increasing include E. Chukchi, Beaufort, S. Canadian Archipelago, Foxe Basin, Davis Strait, Hudson Bay, Hudson Strait, Baffin Bay, Greenland Sea, Denmark Strait, E. Siberian Sea, and W. Bering. In these regions, the straightforward explanation is that summer open water, summer warmth, MaxNDVI, and TI-NDVI all have increased together, though in varying amounts and in all but a few cases are positively correlated (Table 1). The physical explanation is that the decline of sea ice leads to warming over the tundra, and increased vegetation productivity.

Figure 4. Regional trends shown as a percent change from 1982 to 2011 (calculated using the least squares fit method) for (a) summer open water (percent), (b) land summer warmth index (SWI) $\left({ }^{\circ} \mathrm{C}\right.$ month), (c) MaxNDVI (unitless), and (d) Time-Integrated NDVI (unitless). The ocean domain (sea ice) is the $100-\mathrm{km}$ coastal zone and the land domain (SWI, MaxNDVI, and TI-NDVI) is the full tundra as defined by the CAVM [19] and regions indicated in Figure 1. Colored (Grey) stars indicate trend significance at the 95\% (90\%) level or greater.

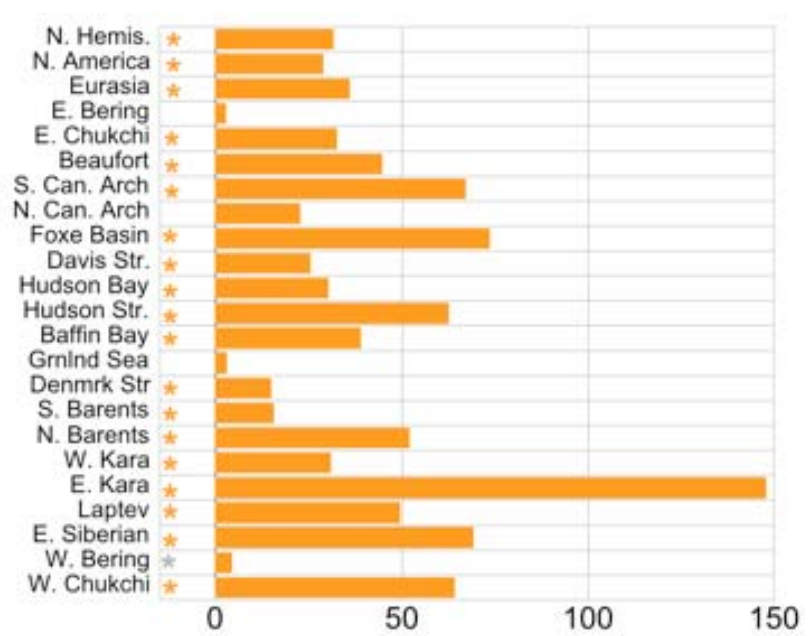

(a) Open Water, 100-km

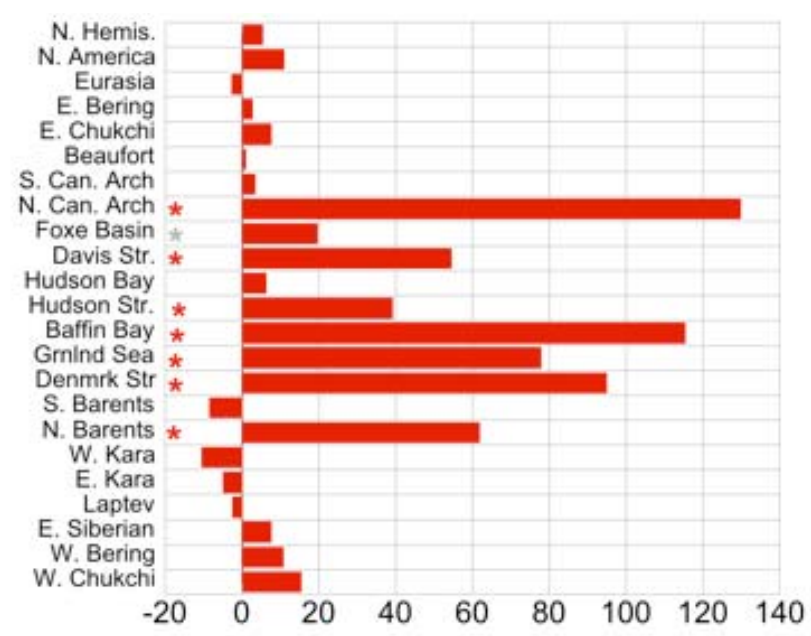

(b) SWI, full tundra 
Figure 4. Cont.

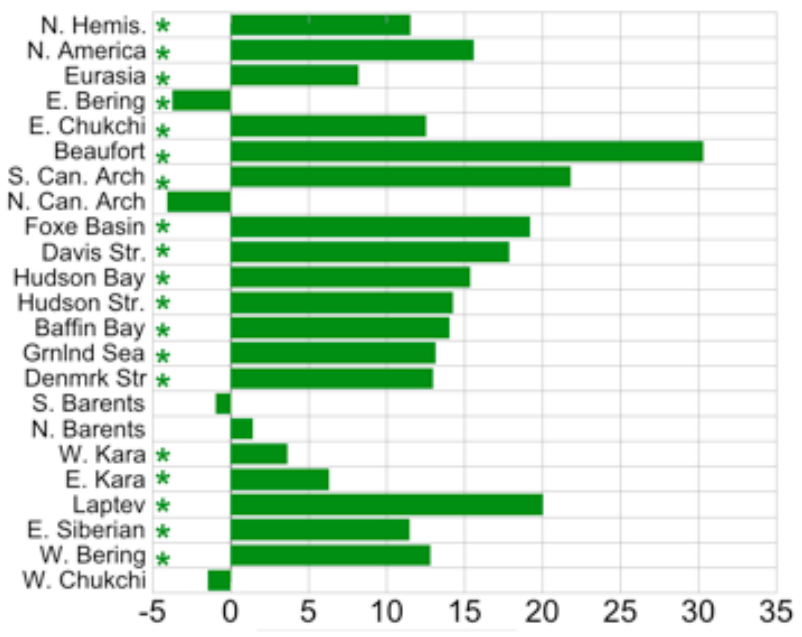

(c) MaxNDVI, full tundra

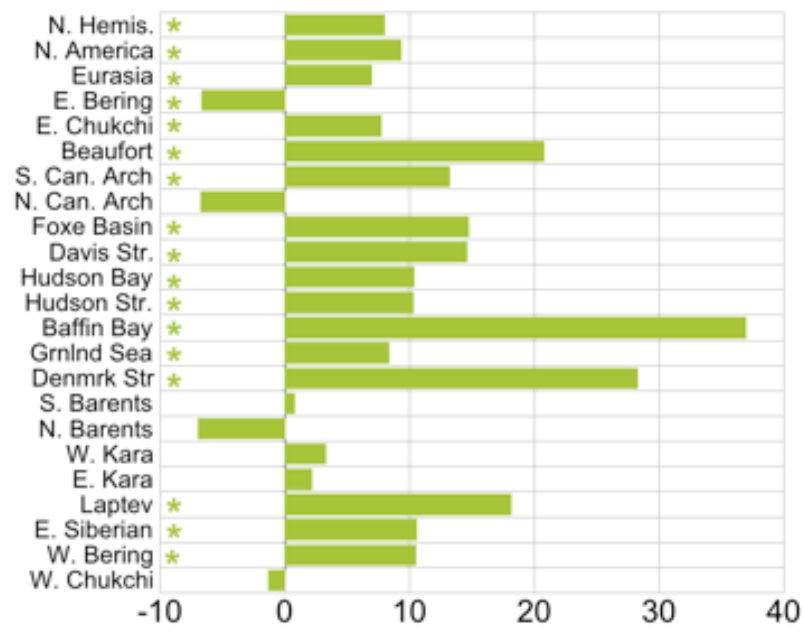

(d) TI-NDVI, full tundra

Table 1. Linearly detrended correlations among sea ice, SWI, open water (OW), TI-NDVI and MaxNDVI over 100-km ocean domain for sea ice and full tundra domain for SWI and NDVI. Bold (Italic) numbers are significant at the 95\% (90\%) or greater level based on Student's t-test.

\begin{tabular}{cccc}
\hline Domain & OW \& SWI & SWI \& TI-NDVI & OW \& TI-NDVI \\
\hline N. Hemisphere & 0.05 & $\mathbf{0 . 5 4}$ & 0.31 \\
N. America & 0.32 & $\mathbf{0 . 5 2}$ & $\mathbf{0 . 4 6}$ \\
Eurasia & 0.19 & $\mathbf{0 . 7 1}$ & 0.12 \\
E. Bering & $\mathbf{0 . 4 0}$ & $\mathbf{0 . 6 2}$ & $\mathbf{0 . 6 0}$ \\
E. Chukchi & 0.23 & $\mathbf{0 . 4 5}$ & 0.33 \\
Beaufort & 0.23 & 0.06 & -0.20 \\
S. Can. Archipelago & $\mathbf{0 . 6 0}$ & $\mathbf{0 . 6 2}$ & $\mathbf{0 . 4 4}$ \\
N. Can. Archipelago & $\mathbf{0 . 5 1}$ & 0.35 & $\mathbf{0 . 4 7}$ \\
Foxe Basin & 0.36 & $\mathbf{0 . 8 0}$ & 0.33 \\
Davis Strait & 0.17 & $\mathbf{0 . 4 4}$ & 0.36 \\
Hudson Bay & $\mathbf{0 . 4 9}$ & $\mathbf{0 . 5 1}$ & $\mathbf{0 . 6 1}$ \\
Hudson Strait & 0.05 & $\mathbf{0 . 4 7}$ & 0.26 \\
Baffin Bay & $\mathbf{0 . 4 1}$ & $\mathbf{0 . 3 8}$ & $\mathbf{0 . 4 0}$ \\
Greenland Sea & $\mathbf{0 . 3 9}$ & $\mathbf{0 . 4 6}$ & $\mathbf{0 . 4 6}$ \\
Denmark Strait & $\mathbf{0 . 6 5}$ & $\mathbf{0 . 5 1}$ & 0.31 \\
S. Barents & 0.22 & $\mathbf{0 . 4 5}$ & 0.24 \\
N. Barents & 0.01 & $\mathbf{0 . 6 1}$ & -0.25 \\
W. Kara & 0.28 & $\mathbf{0 . 6 2}$ & 0.06 \\
E. Kara & 0.11 & $\mathbf{0 . 7 1}$ & 0.07 \\
Laptev & $\mathbf{0 . 5 8}$ & $\mathbf{0 . 6 3}$ & 0.31 \\
E. Siberian & $\mathbf{0 . 5 1}$ & $\mathbf{0 . 7 3}$ & $\mathbf{0 . 5 7}$ \\
W. Bering & -0.21 & $\mathbf{0 . 4 1}$ & 0.08 \\
W. Chukchi & 0.32 & $\mathbf{0 . 6 5}$ & $\mathbf{0 . 3 9}$ \\
\hline
\end{tabular}


The S. Barents, W. Kara, E. Kara, and Laptev form a similar pattern group with increased summer open water but SWI declines and increases of MaxNDVI and TI-NDVI. The exception is that MaxNDVI is weakly decreasing in the S. Barents. This group of regions are close in proximity and the declines in SWI are consistent with large-scale cooling over the Eurasian continent in this sector $\left(90^{\circ} \mathrm{E}-100^{\circ} \mathrm{E}\right)$ that has been noted in AVHRR surface temperature trends (See Figure $1 \mathrm{~b}, \mathrm{c}$ of Comiso 2006) [57]. The cooling over Eurasia is most likely driven by the large-scale climate as opposed to local ice-ocean-atmosphere-land processes. A recent study suggests that the large-scale cooling over Eurasia is associated with increased cloudiness [58]. Correlations between SWI and TI-NDVI are large and significant for all four regions. With the exception of the Laptev Sea, the correlations between OW and SWI are weaker than the average regional correlations $(0.34)$, consistent with the notion that variance in summer warmth is explained by factors other than OW when compared to other regions.

The E. Bering, W. Chukchi, and Northern Canadian Archipelago form a group where summer open water and SWI are increasing while MaxNDVI and TI-NDVI are declining. Correlations between SWI and TI-NDVI are positive and significant at the $90 \%$ level or greater, so more warmth favors higher TI-NDVI. This suggests that some other factors are impacting the vegetation productivity. Bieniek (2012) [59] explored processes that could impact NDVI declines in E. Bering such as reductions in summer moisture, snowfall reductions, reduced water availability due to draining of surface water from thawing permafrost and insect infestation, however due to various data constraints a clear answer has not emerged. We conclude that factors other than temperature are leading to reductions in MaxNDVI and TI-NDVI in these regions.

The N. Barents has a unique trend pattern of increases in OW, SWI and MaxNDVI and declines in TI-NDVI. SWI and TI-NDVI have a correlation of 0.61 (95\% level significance) while OW and SWI are not correlated. OW and TI-NDVI are actually weakly negatively correlated. This suggests that as open water increases the TI-NDVI will decline. Open water in this relatively warm oceanic area would be consistent with enhanced storminess and increased snowfall during spring or fall that could reduce TI-NDVI. Snow cover simulations from several reanalysis-driven snow cover reconstructions suggest increasing trends in annual maximum snow accumulation on Svalbard and Franz Josef Land over the past 30 years [60] which is consistent with observed increases in cold season precipitation over the Barents Sea sector of the Arctic and increases in winter snow depths over northern Eurasia [61].

The regions in North America in Figure 4 that display SWI increases of more than $20 \%$ percent include North Canada Archipelago, Davis Strait, Hudson Strait, Baffin Bay, Greenland, and Denmark Strait. These areas are also ones that currently do not display some period of a cooling trend during summer [62]. Due to the distinctly different temperature trends in this region, North America has been split into two regions (Western and Eastern North America) and time series are displayed along with those of Eurasia in the next section to quantify trend changes over time.

\subsection{Regional Trend Changes}

Open water in the $100-\mathrm{km}$ coastal zone has increased in all three regions, but the most in Eurasia during 1982-2011 (Figure 5a). In Eastern North America, open water has steadily increased and does not display a break point, or a change in trend. The break-fit analysis determined a break close to the time-series starting point (1985) that had a large uncertainty (10 years), so it is reasonable to conclude 
that the likelihood of a break in this time series is low. In Western North America, the increasing trend slowed down after the middle of the 1990s, while in Eurasia the positive trend accelerated after the middle of the 2000s. The increase of ice-free areas near the Eurasian coast has been noted in an observational study particularly in the E. Siberian and Laptev Seas [63]. By definition, summer open water increase is expected to slow down since at some point all of the ice may be gone during the May to August period within $100-\mathrm{km}$ of the coasts. But that point has not been reached yet and the time series has values between $40 \%$ and $70 \%$.

Summer warmth (SWI) has increased overall for the Arctic over the 1982-2011 period but displays notably different trends in the three regions (Figure 5b). It has steadily increased in Eastern North America with a very small chance of any breaks in the trend. In Western North America, the SWI has increased until the late 1990s and has declined since, which coincides with a slowing down of the rate of open water increase. The Eurasian region displays warming until the middle of the 2000s and SWI has been declining since, which corresponds to an increasing rate in OW. If OW and SWI are intimately tied then different processes are occurring in Eurasia and Western North America. Observations have noted that warming both globally and in the Arctic has stalled during the last decade $[64,65]$, which is consistent with our regional trends.

The MaxNDVI is increasing in all of the regions and without notable break points in Eurasia and Eastern North America, but Western North America shows an accelerated increase since the break point that occurred in the middle of the 2000s (Figure 6a). This increase over Western North America in MaxNDVI can be primarily attributed to the Beaufort region, and less so to the E. Chukchi and Hudson Bay (not shown). The TI-NDVI displays overall positive trends with the exception of a break in 2005 for Eurasia after which the trends are negative (Figure 6b).

The MaxNDVI increase over Western North America shows up as a significant break point in the time series and was large enough to warrant further examination. Pinzon [66] found that the jump over North America is indeed an artifact due to the inclusion of very low values in NOAA14 at the end of September to the beginning of October that affected the calibration parameters for NOAA7-NOAA14. The low values were not filtered since they satisfied the $95 \%$ confidence levels. The calibration has been revised and tested with success with a new procedure to better identify potential bad pixels and the subsequent version of NDVI3g will not have these artifacts.

Comparison of our analysis with NDVI from shorter records such as MODIS suggests that the vegetation productivity has continued to increase over the last decade. Over the western Eurasian Arctic, Dutrieux et al. [16] find an increasing TI-NDVI trend for the 2000-2011 period using the MODIS NDVI. In a global study that compares MODIS and GIMMS NDVI3g trends, MODIS contains more positive NDVI trends compared to NDVI3g over the 2000-2010 period in the North American and Eurasian Arctic [67]. Evidence of increasing MODIS NDVI tundra trends suggests that the detected break points in the time series of MaxNDVI for Eastern North America and TI-NDVI for Eurasia may be in part related to the known NDVI3g processing issue. In a paper that examined break point methodology applied to the NDVI3g in Alaska, Forkel et al. [68] suggested caution since erroneous break points may lead to incorrect conclusions but found that these methods offer good potential to detect trend changes and possible disturbances in the NDVI time series. 
Figure 5. (a) Open water (average weekly percent) and (b) summer warmth index $\left({ }^{\circ} \mathrm{C}\right.$ month) time series for Eurasia (Orange), Western North America (red) and Eastern North America (blue). Trend lines with break points and their associated error are identified for each time series along with the slopes before (top left corner) and after the break points (bottom left corner). Noteworthy break points are identified by a bold star based on the methodology of Mudelsee $[45,46]$.

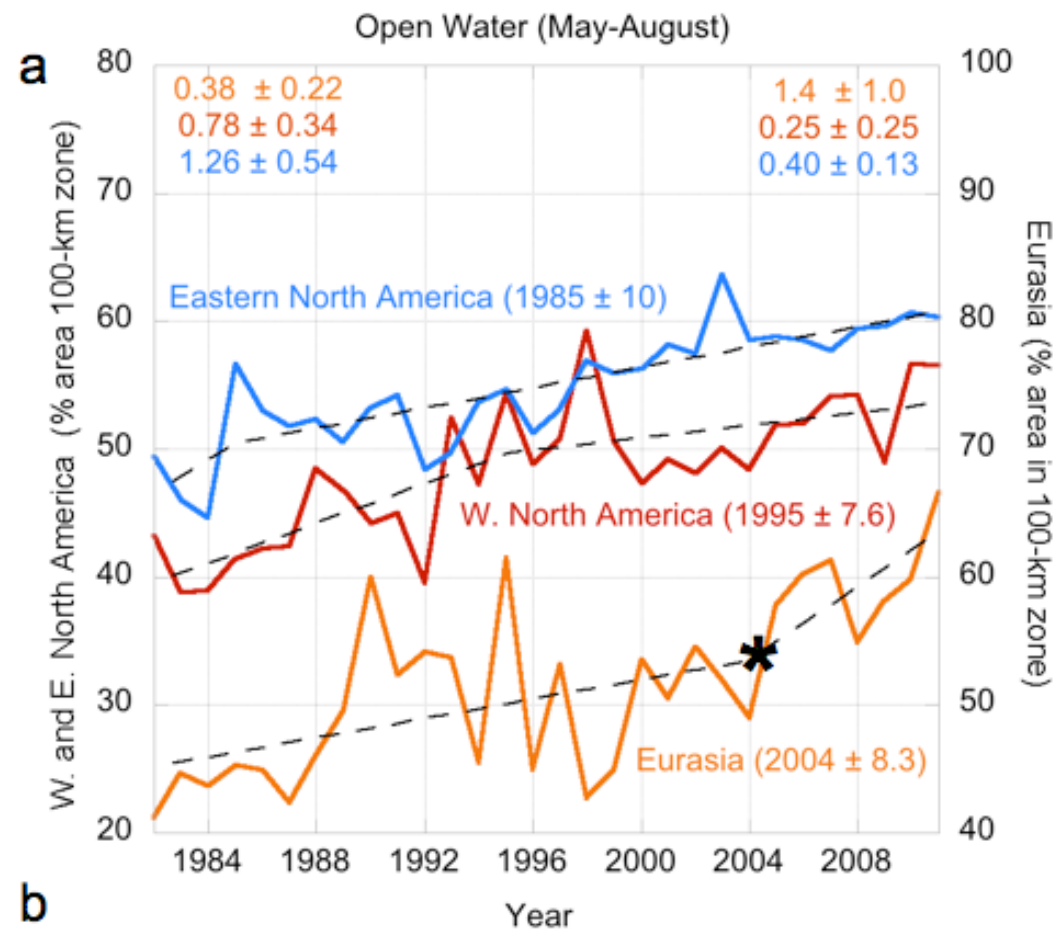

Summer Warmth Index (May-August)

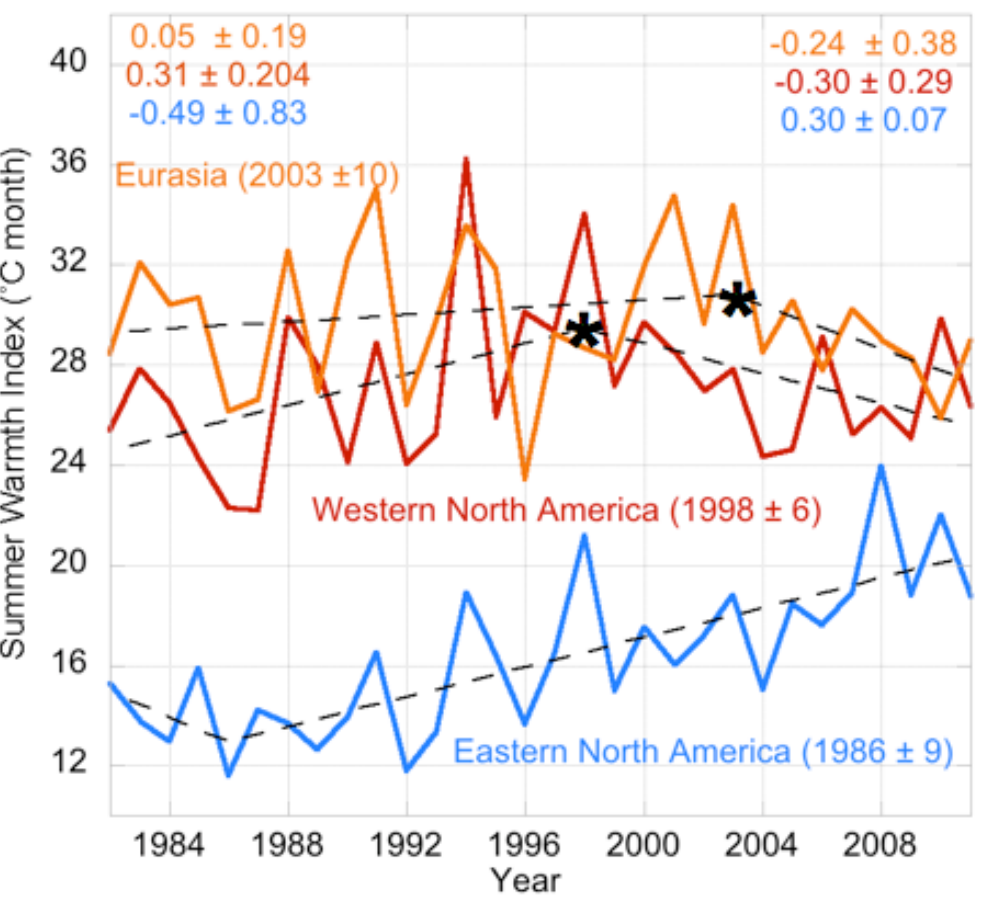


Figure 6. (a) Maximum NDVI (unitless) and (b) Time Integrated NDVI (unitless) time series for Eurasia (Orange), Western North America (red) and Eastern North America (blue). Trend lines with break points and their associated error are identified for each time series along with the slopes before (top left corner) and after the break points (bottom left corner). Noteworthy break points are identified by a bold star based on the methodology of Mudelsee [45,46].

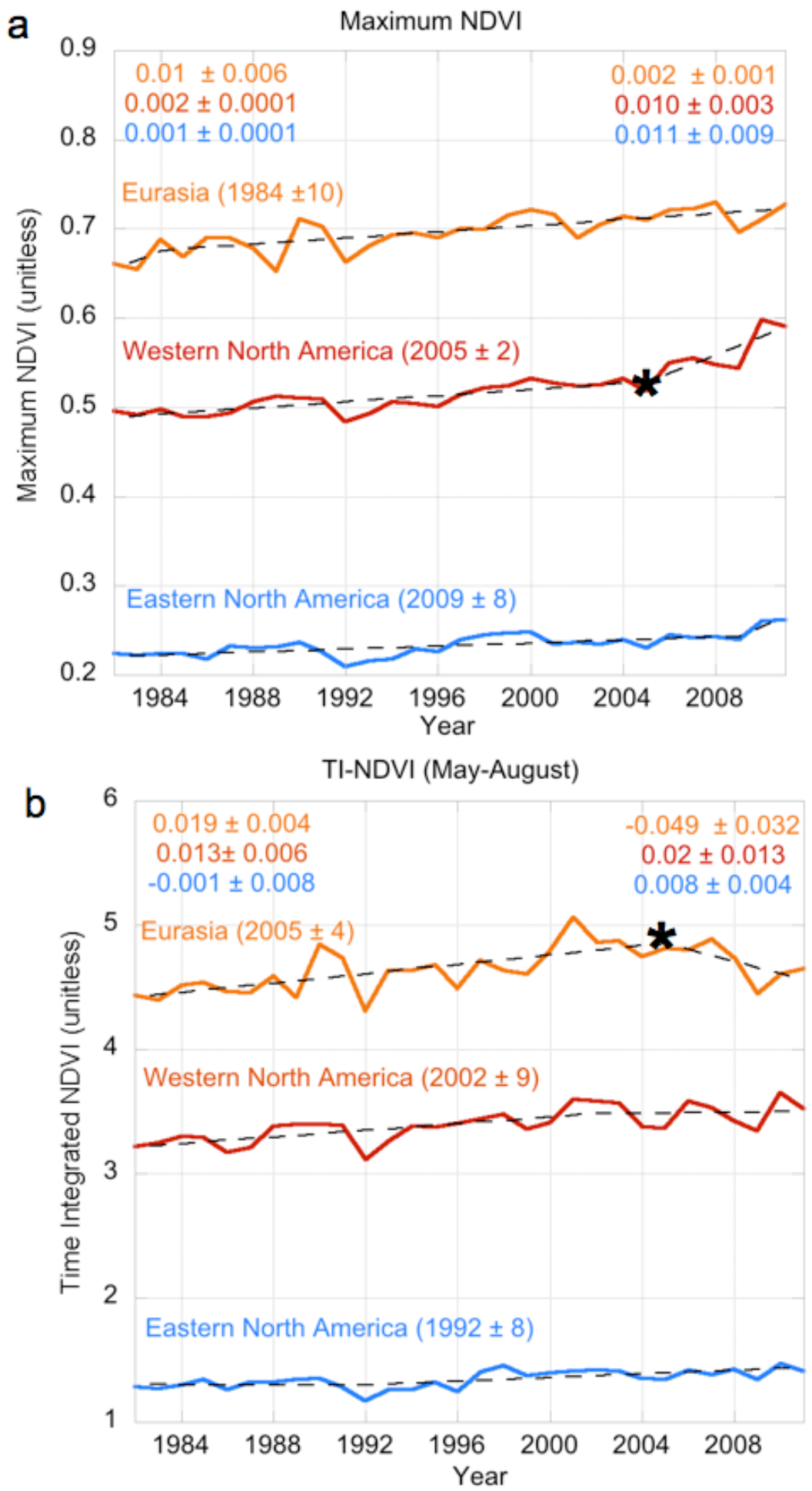




\subsection{Consequences of Large-Scale and Long-Term Climate Variability for Tundra Vegetation}

The Arctic is characterized by large-scale climate variability on interannual to multi-decadal time scales that can impact the biosphere [55], so trends over relatively short record lengths should be attributed with caution. In fact, short-term greening and browning trends have been linked to large-scale climate variations, such as El Niño or volcanic eruptions, in a global [69] and an Alaska [2] NDVI study. The influence of the large-scale climate on the Arctic is well known during winter when large transports of heat from the equatorial regions to the high latitudes are maximized coinciding with the strongest equator-to-pole temperature gradients to attain a global energy balance. The amplified response to global warming in the Arctic results from sea-ice decline [15] as well as increased poleward heat and moisture transport [70]. Recent work shows that the increase in annual Eurasian Arctic river discharge is not due to local moisture recycling but rather due to increased moisture transport from lower latitudes which falls as snow during winter and melts in the warm season to enhance river flow [71]. In this section we look beyond the Arctic and the satellite era, over larger spatial and longer temporal scales, for factors that may impact arctic vegetation.

Summer (June-August) average sea-level pressure (slp) displays decadal changes (Figure 7a). Climatological (1981-2010) slp during summer is characterized by low pressure over Eurasia, the central Arctic, and North America and higher pressure over the Beaufort Sea and the Gulf of Alaska. Based on the break point analysis for SWI in Western North America, summer slp averages are constructed for 1982-1998 (Figure 7c) and 1999-2011 (Figure 7d). Note that the results are very similar if the Eurasian break point of 2003 is chosen for constructing the composite slp averages. Since 1999 the slp has decreased over the continents, particularly Eurasia and has increased over the Arctic Ocean and around Greenland (Figure 7b). A strengthening of the Beaufort High during summer has been documented [72] along with stronger onshore winds in northern Alaska [73]. The reduced slp over Eurasia is consistent with the strengthening of the positive phase of the Arctic Rapid change Pattern (ARP) that links sea-ice loss to enhanced poleward heat and moisture transport induced by recent shifts in this circulation pattern [74]. The slp pattern in Figure $7 \mathrm{~b}$ resembles the recent negative phase of the summer Arctic Oscillation found to be more common since 1996 [75]. Lower slp is associated with increased cloud cover, which acts to cool the surface and is consistent with the SWI trends since 2003. At this stage, we only present slp evidence since the long-term remote sensing cloud data set based on the AVHRR are robust only until 2004 [76] and an updated data set that is expected in the future is necessary for such an analysis. These slp composites [77] suggest that changes in the large-scale circulation are likely playing a key role in the recent decline in SWI over Eurasia and Western North America. We can only speculate on whether this summer cooling will continue and for how long. We may expect that if this cooling continues then MaxNDVI increases will likely decline at some point due to reduced available warmth such as has been seen after the eruption of Pinatubo which reduced temperatures and MaxNDVI [2]. 
Figure 7. June to August averaged sea level pressure (slp) (a) climatology (1981-2010), (b) difference between 1999-2011 and 1982-1998, (c) 1982-1998 average, and (d) 1999-2011 average. Data for images were provided by the NOAA/ESRL Physical Sciences Division, Boulder Colorado [77].
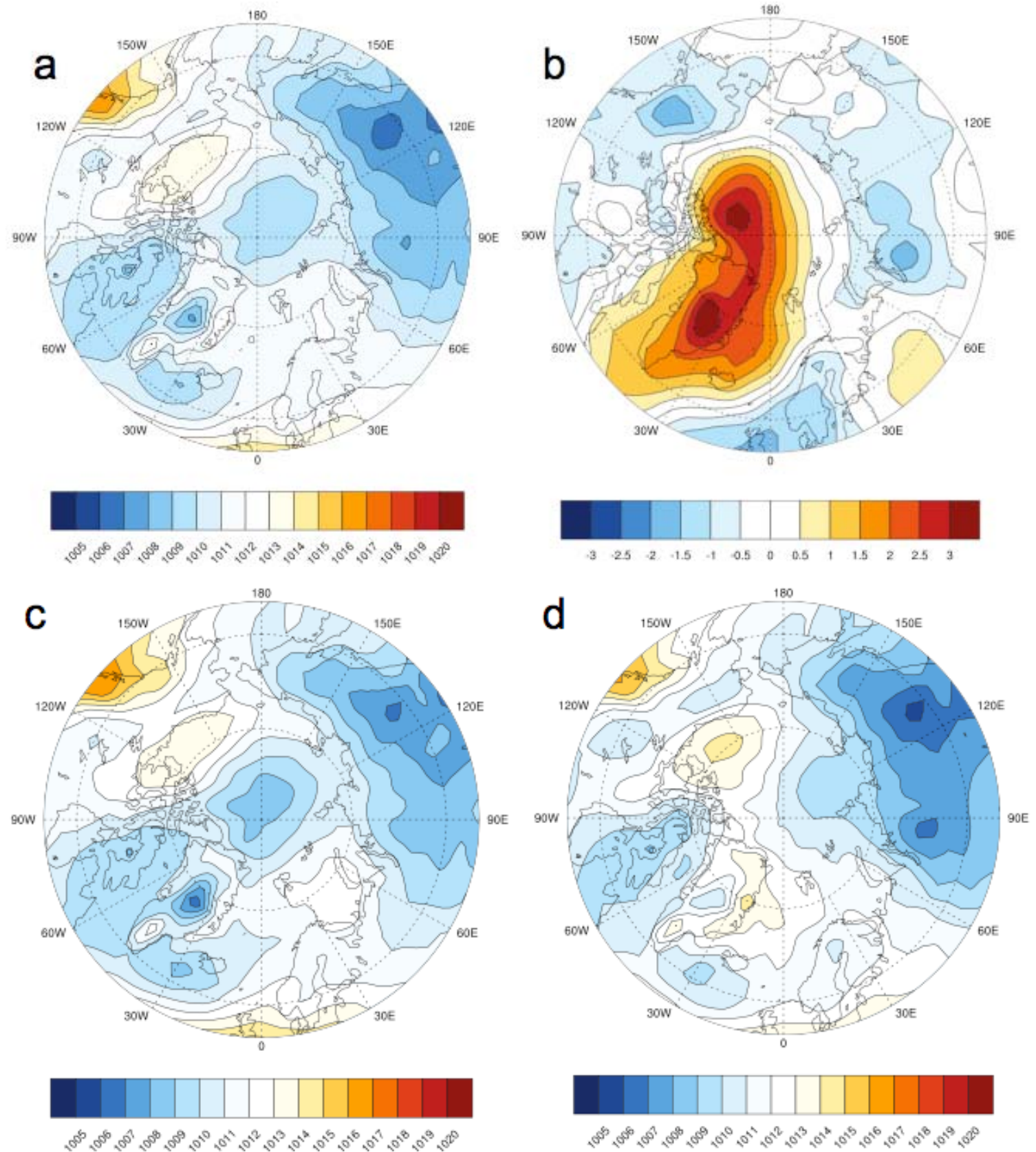

The recent cooling over Eurasia is next placed into a longer-term context by comparing the AVHRR SWI trends with those that go further back using meteorological station data over the high latitude Arctic regions. For information about station data sources see Bekryaev [13]. Meteorological station SWI trends (Figure 8a) peak in 2000 and also show a decline since about 2005, corroborating the remote sensing results. Despite recent declines, SWI over Eurasia is higher in the last few decades than it has been since the 1930s when the record begins. Figure $8 \mathrm{~b}$ displays seasonal SAT anomalies that show the warming of the 1940s, a cooler 1960s and recent warming in the fall and winter seasons. The recent summer and spring warming is quite different and much warmer than what was present in 
the 1940s. Over North America, station SWI (Figure 9a) was higher in the 1940s, followed by a decline and then an increase in the last decade. The mean SWI is lower over North America than Eurasia due to the proximity to perennial sea ice and displays large interannual variability, due to strong influences from low-latitude climate variations related to El Niño/Southern Oscillation or the Pacific North American (PNA) Pattern [78]. Figure 9b displays seasonal SAT time series for North America and the fall, winter, and summer exhibit large warming in the 1940s, cooling in the 1960-70s, and warming since 1990. Spring SAT variations have been comparatively small until the 1980s when they began to increase. The station-based SWI reached a peak in 1998 and has declined since, in agreement with the AVHRR surface temperature-based SWI. The mean SWI values based on station data are generally cooler than those based on AVHRR LSTs, which is consistent with the comparison of in situ data with numerous remote sensing products performed by Urban et al. [78] for the period of 2000 to 2005. They find that land surface temperature and air temperature are correlated to some extent but since they measure different things, they are not expected to be identical.

Figure 8. Time series of (a) SWI and (b) seasonal surface air temperature (SATs) anomalies for Eurasia based on 2-m air temperatures from meteorological stations (see locations in Figure A1b). Trends shown in the panels are for the period 1982-2008. The $\mathrm{x}$-axis for both panels is shown at the bottom of the figure.

a

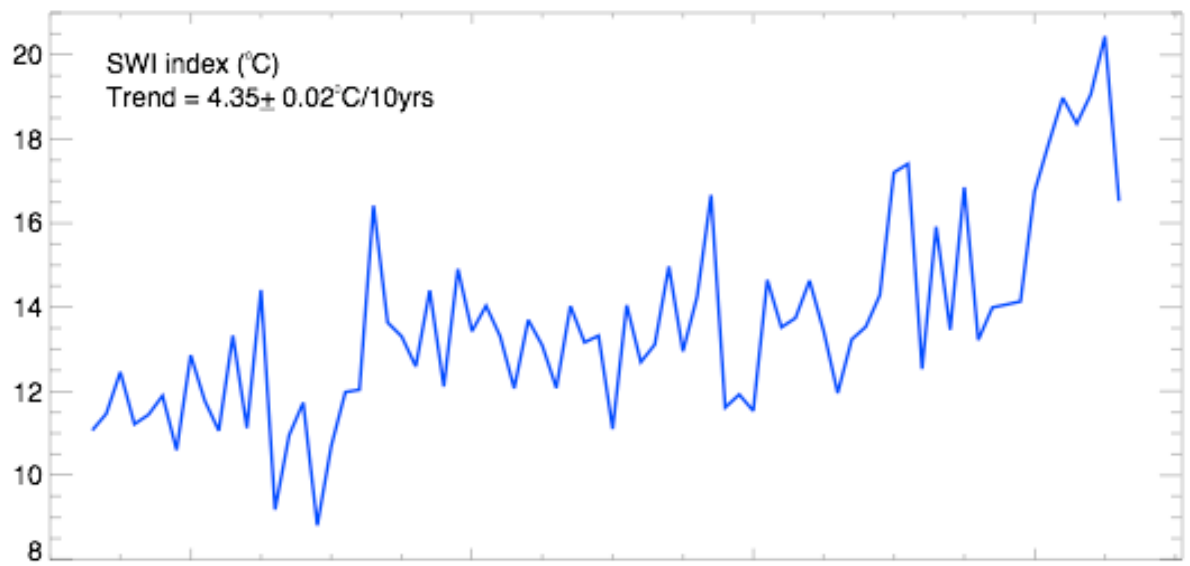

b

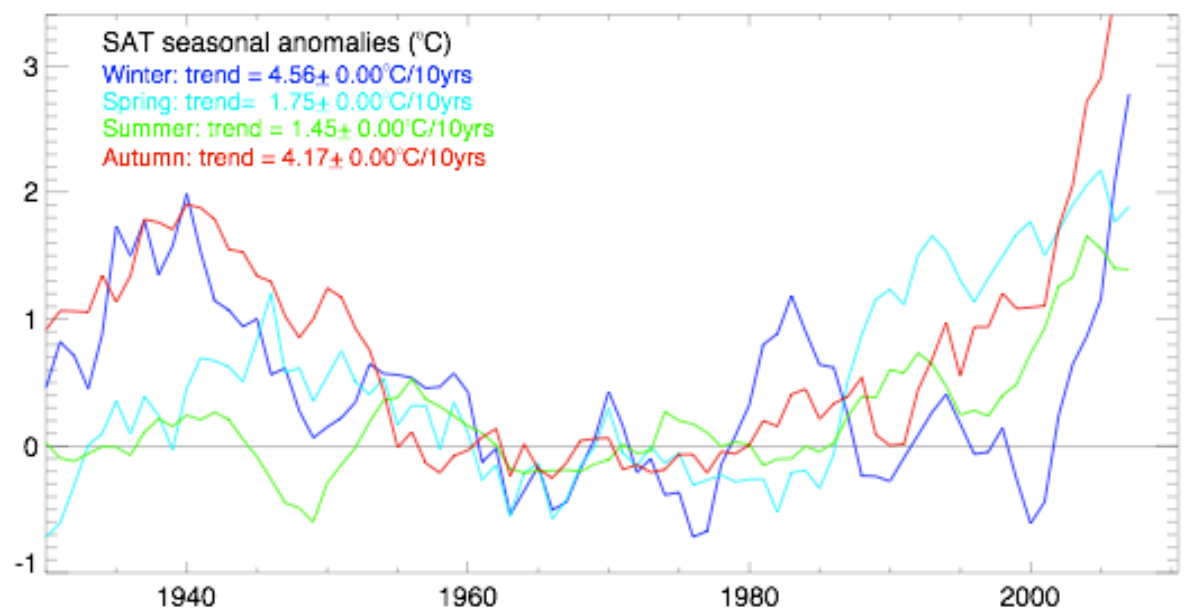


Figure 9. Time series of (a) SWI and (b) seasonal surface air temperature (SATs) anomalies for North America based on 2-m air temperatures from meteorological stations (see locations in Figure A1b). Trends shown in the panels are for the period 1982-2008. The $\mathrm{x}$-axis for both panels is shown at the bottom of the figure.
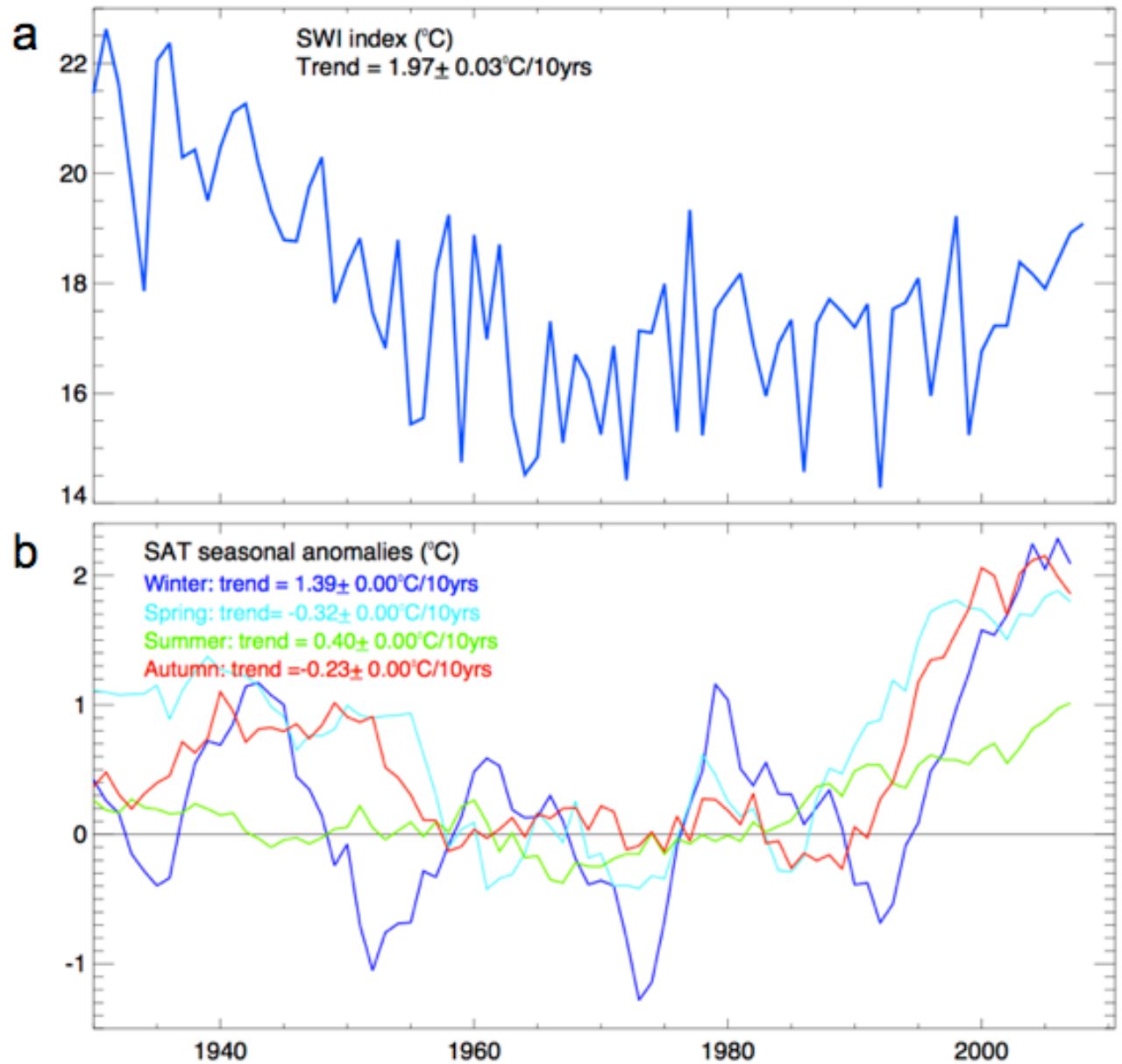

\section{Conclusions}

This study employs remote sensing data in the Arctic to document recent trends and trend changes of sea ice, land surface temperatures, and tundra NDVI. The unique features of this study include the examination of tundra vegetation changes in the context of various measures of climate variability, such as sea ice and large-scale circulation. During the 1982-2011 period, on a pan-Arctic scale, summer (May-August) open water has increased, the land surface has warmed, and NDVI has increased. Trends over the 1982-2008 period are compared to those over the 1982-2011 period to reveal that spring sea-ice declines have strengthened in the Arctic Ocean but weakened at lower latitudes (e.g., Bering Sea, Sea of Okhotsk, Hudson Bay, and Baltic Sea). Summer open water has been reduced in the Greenland Sea, Hudson Bay, and the Bering Sea, while it has increased in the Barents, Kara and Laptev Seas and at the mouth of the McKenzie River in the Beaufort Sea. SWI warming has slowed down over most of Eurasia and North America except the Taimyr Peninsula, Baffin Island and the northern Canadian Archipelago, where warming rates have increased. MaxNDVI rates of increase have slowed down over most of Eurasia and Alaska while they have increased over continental Canadian tundra and Baffin Island. 
Based on warming patterns [62], the Arctic was divided into three areas Eurasia, Western North America and Eastern North America. Eastern North America displays steady warming trends and increases in MaxNDVI and TI-NDVI over the 1982-2011 period. Western North America and Eurasia display SWI declines since 1998 and 2003, respectively. In Western North America, the MaxNDVI rate of increase has accelerated since 2005 while TI-NDVI continues to steadily increase. MaxNDVI is increasing steadily over Eurasia but TI-NDVI has declined since 2005. The decline in TI-NDVI over Eurasia begins around the time of the SWI declines, is consistent with the correlation analysis, and is most likely primarily a real feature. However, since analysis of MODIS TI-NDVI [16] does not show similar declines over Eurasia, it may be partially related to a GIMMS NDVI3g processing issue. The MaxNDVI increase since 2005 over Western North America is not consistent with changes in SWI so could be associated with an NDVI3g filtering issue or may be indicative of different processes operating in this region.

Composites of multi-year summer (June-August) sea level pressure from the NCEP/NCAR reanalysis data reveal that since the late 1990's high pressure over the Arctic and Greenland has strengthened while slp has decreased over continental areas. The general lower pressure over Eurasia is consistent with lower land surface temperatures associated with cloudiness that accompany lower slp. The area of warming around Greenland is consistent with the generally higher pressures that reduce the incidence of cloudiness due to subsiding air. In addition, these pressure patterns suggest that the recent declines in land surface temperatures are likely associated with large-scale circulation changes in addition to local processes in the Arctic. Even though Eurasia has seen a decline in SWI over the last decade in the satellite data, analysis of SWI based on station data reveals that the continent is warmer during the last decade than it has been in summer over the 1930-2008 period.

Future work in this area should aim to quantify the importance of local versus extra-Arctic climate processes for vegetation changes, since both appear to impact tundra vegetation. Targeted GCM experiments with specified sea ice and sea surface temperatures are needed to quantify the contribution of the large-scale climate to temperature changes that are occurring in the Arctic.

The AVHRR NDVI data have provided a long and consistent record that has permitted the monitoring from space of the Arctic, a region so remote that it is not possible to monitor only from the ground. The preparation of remote sensing data sets for climate studies is a time-consuming task and is in fact an ongoing process. Each new analysis highlights possible new concerns about the data, which can then be addressed in the next iteration. These data should be viewed as the best possible version at any given time that will be improved in the future. Only through comparison with other data sets with an interdisciplinary mindset, will it be possible to understand the complex links between the components of the arctic Earth system.

\section{Acknowledgments}

This study was supported by grants NSF ANS-0732885, NSF ARC-0902175, NASA Land Cover Land Use Change on the Yamal Peninsula. This work benefitted from conversations with Ross Brown, Chris Derksen, David Robinson and Walt Meier. Manfred Mudelsee is thanked for sharing his FORTRAN code for the BREAKFIT programs and providing assistance with interpreting results. We thank four anonymous reviewers for their contributions in greatly improving this paper. 


\section{Conflicts of Interest}

The authors declare no conflict of interest.

\section{References}

1. Myneni, R.B.; Keeling, C.D.; Tucker, C.J.; Asrar, G.; Nemani, R.R. Increased plant growth in the northern high latitudes from 1981 to 1991. Nature 1997, 386, 698-702.

2. Jia, G.J.; Epstein, H.E.; Walker, D.A. Greening of arctic Alaska, 1981-2001. Geophys. Res. Lett. 2003, 30, 2067.

3. Stow, D.A.; Hope, A.; McGuire, D.; Verbyla, D.; Gamon, J.; Huemmrich, F.; Houston, S.; Racine, C.; Sturm, M.; Tape, K.; et al. Remote sensing of vegetation and land-cover change in Arctic Tundra Ecosystems. Remote Sens. Environ. 2004, 89, 281-308.

4. Goetz, S.J.; Bunn, A.G.; Fiske, G.J.; Houghton, R.A. Satellite-observed photosnthetic trends across boreal North America associated with climate and fire disturbance. Proc. Natl. Acad. Sci. USA 2005, 102, 13521-13525.

5. Bunn, A.G.; Goetz, S.J.; Kimball, J.S.; Zhang, K. Northern high-latitude ecosystems respond to climate change. EOS Trans. AGU 2007, 88, 333-340.

6. Verbyla, D. The greening and browning of Alaska based on 1982-2003 satellite data. Glob. Ecol. Biogeogr. 2008, 17, 547-555.

7. Walker, D.A.; Bhatt, U.S.; Comiso, J.C.; Epstein, H.E.; Gould, W.A.; Henry, G.H.R.; Jia, G.J.; Kokelj, S.V.; Lantz, T.C.; Mercado-Diaz, J.A.; et al. Arctic. Land: Vegetation, in state of the climate in 2010. Bull. Am. Meteorol. Soc. 2011, 92, S150-S152.

8. Xu, L.; Myneni, R.B.; Chapin, F.S., III; Callaghan, T.V.; Pinzon, J.E.; Tucker, C.J.; Zhu, Z.; Bi, J.; Ciais, P.; Tommervik, H.; et al. Temperature and vegetation seasonality diminishment over northern lands. Nat. Clim. Chang. 2013, 3, 1-6.

9. Shippert, M.M.; Walker, D.A.; Auerbach, N.A.; Lewis, B.E. Biomass and leaf-area index maps derived from SPOT images for Toolik Lake and Imnavait Creek areas. Alsk. Polar Rec. 1995, 31, $147-154$.

10. Walker, D.A.; Epstein, H.E.; Jia, G.J.; Balser, A.; Copass, C.; Edwards, E.J.; Gould, W.A.; Hollingsworth, J.; Knudson, J.; Maier, H.A. Phytomass, LAI, and NDVI in northern Alaska: Relationships to summer warmth, soil $\mathrm{pH}$, plant functional types, and extrapolation to the circumpolar Arctic. J. Geophys. Res.-Oceans 2003, 108, 8169.

11. Raynolds, M.K.; Walker, D.A.; Epstein, H.E.; Pinzon, J.E.; Tucker, C.J. A vegetation map of the arctic tundra biome $(1: 1,750,000$ scale): II. Analysis of the dstribution of phytomass and vegetation types. J. Veg. Sci. 2004, 3, 403-411.

12. Epstein, H.E.; Raynolds, M.K.; Walker, D.A.; Bhatt, U.S.; Tucker, C.J.; Pinzon, J.E. Dynamics of aboveground phytomass of the circumpolar Arctic tundra during the past three decades. Environ. Res. Lett. 2012, doi: 10.1088/1748-9326/7/1/015506.

13. Bekryaev, R.V.; Polyakov, I.V.; Alexeev, V.A. Role of polar amplification in long-term surface air temperature variations and modern Arctic warming. J. Clim. 2010, 23, 3888-3906. 
14. Bhatt, U.S.; Walker, D.A.; Raynolds, M.K.; Comiso, J.C.; Epstein, H.E.; Jia, G.; Gens, R.; Pinzon, J.E.; Tucker, C.J.; Tweedie, C.E.; et al. Circumpolar Arctic tundra vegetation change is linked to sea ice decline. Earth Interact. 2010, 14, 1-20.

15. Serreze, M.C.; Barry, R.G. Processes and impacts of Arctic amplification: A research synthesis. Glob. Planet. Chang. 2011, 77, 85-96.

16. Dutrieux, L.P.; Bartholomeus, H.; Herold, M.; Verbesselt, J. Relationships between declining summer sea ice, increasing temperatures and changing vegetation in the Siberian Arctic tundra from MODIS time series (2000-11). Environ. Res. Lett. 2012, 7, 044028.

17. Lawrence, D.M.; Slater, A.G.; Tomas, R.A.; Holland, M.M.; Deser, C. Accelerated Arctic land warming and permafrost degradation during rapid sea ice loss. Geophys. Res. Lett. 2008, 35, L11506.

18. Bhatt, U.S.; Alexander, M.A.; Deser, C.; Walsh, J.E.; Miller, J.S.; Timlin, M.S.; Scott, J.; Tomas, R.A. The Atmospheric Response to Realistic Reduced Summer Arctic Sea Ice Anomalies. In Arctic Sea Ice Decline: Observations, Projections, Mechanisms, and Implications; DeWeaver, E.T., Bitz, C.M., Tremblay, L.-B., Eds.; American Geophysical Union: Washington, DC, USA, 2008; pp. 91-110.

19. Higgins, M.E.; Cassano, J.J. Northern Alaskan land surface response to reduced Arctic sea ice extent. Clim. Dyn. 2012, 38, 2099-2113.

20. Hu, F.S.; Higuera, P.E.; Walsh, J.E.; Chapman, W.L.; Duffy, P.A.; Brubaker, L.B.; Chipman, M.L. Tundra burning in Alaska: Linkages to climatic change and sea ice retreat. J. Geophys. Res.-Oceans 2010, 115, G04002.

21. Walker, D.A.; Raynolds, M.K.; Daniëls, F.J.A.; Einarsson, E.; Elvebakk, A.; Gould, W.A.; Katenin, A.E.; Kholod, S.S.; Markon, C.J.; Melnikov, E.S.; et al. The circumpolar arctic vegetation map. J. Veg. Sci. 2005, 16, 267-282.

22. Raynolds, M.K.; Walker, D.A.; Maier, H.A. Effects of deglaciation on circumpolar distribution of arctic vegetation. Remote Sens. Environ. 2009, 102, 271-281.

23. Elmendorf, S.C.; Henry, G.H.R.; Hollister, R.D.; Bjork, R.G.; Bjorkman, A.D.; Callaghan, T.V.; Collier, L.S.; Cooper, E.J.; Cornelissen, J.H.C.; Day, T.A.; et al. Global assessment of experimental climate warming on tundra vegetation: heterogeneity over space and time. Ecol. Lett. 2012, 15, 164-175.

24. Walker, D.A.; Leibman, M.O.; Epstein, H.E.; Forbes, B.C.; Bhatt, U.S.; Raynolds, M.K.; Comiso, J.C.; Gubarkov, A.A.; Khomutov, A.V.; Jia, G.J.; et al. Spatial and temporal patterns of greenness on the Yamal Peninsula, Russia: Interactions of ecological and social factors affecting the Arctic normalized difference vegetation index. Environ. Res. Lett. 2009, 4, 045004.

25. Walker, D.A.; Forbes, B.C.; Leibman, M.O.; Epsteiin, H.E.; Bhatt, U.S.; Comiso, J.C.; Drozdov, D.S.; Gubarkov, A.A.; Jia, G.J.; Karlejaärvi, E.; et al. Cumulative Effects of Rapid Land-Cover and Land-Use Changes on the Yamal Peninsula, Russia. In Eurasian Arctic Land Cover and Land Use in a Changing Climate; Gutman, G., Groismann, P., Reissel, A., Eds.; Springer Verlag: Berlin/Heidelberg, Germany, 2011. 
26. Hudson, J.M.G.; Henry, G.H.R. Increased plant biomass in a High Arctic heath community from 1981 to 2008. Ecology 2009, 90, 2657-2663.

27. Elmendorf, S.C.; Henry, G.H.R.; Hollister, R.D.; Björk, R.G.; Boulanger-Lapointe, N.; Cooper, E.J.; Cornelissen, J.H.C.; Day, T.A.; Dorrepaal, E.; Elumeeva, T.G.; et al. Plot-scale evidence of tundra vegetation change and links to recent summer warming. Nat. Clim. Chang. 2012, 2, 453-457.

28. Tape, K.; Sturm, M.; Racine, C. The evidence for shrub expansion in Northern Alaska and the Pan-Arctic. Glob. Chang. Biol. 2006, 12, 686-702.

29. Tape, K.D.; Hallinger, M.; Welker, J.M.; Ruess, R.W. Landscape heterogeneity of shrub expansion in Arctic Alaska. Ecosystems 2012, 15, 711-724.

30. Myers-Smith, I.H.; Forbes, B.C.; Wilmking, M.; Hallinger, M.; Lantz, T.; Blok, D.; Tape, K.D.; Macias-Fauria, M.; Sass-Klaassen, U.; Lévesque, E.; et al. Shrub expansion in tundra ecosystems: Dynamics, impacts and research priorities. Environ. Res. Lett. 2011, 6, 045509.

31. Forbes, B.C.; Fauria, M.M.; Zetterberg, P. Russian Arctic warming and "greening" are closely tracked by tundra shrub willows. Glob. Chang. Biol. 2010, 16, 1542-1554.

32. Macias-Fauria, M.; Forbes, B.C.; Zetterberg, P.; Kumpula, T. Eurasian Arctic greening reveals teleconnections and the potential for structurally novel ecosystems. Nat. Clim. Chang. 2012, 2, 613-618.

33. Parmentier, F.-J.W.; Christensen, T.R.; Sørensen, L.L.; Rysgaard, S.; McGuire, A.D.; Miller, P.A.; Walker, D.A. The impact of lower sea-ice extent on Arctic greenhouse-gas exchange. Nat. Clim. Chang. 2013, 3, 195-202.

34. Zhang, J.; Walsh, J.E. Thermodynamic and hydrological impacts of increasing greenness in northern high latitudes. J. Hydrometeorol. 2006, 7, 1147-1163.

35. Jeong, J.-H.; Kug, J.-S.; Kim, B.-M.; Min, S.-K.; Linderholm, H.W.; Ho, C.-H.; Rayner, D.; Chen, D.; Jun, S.-Y. Greening in the circumpolar high-latitude may amplify warming in the growing season. Clim. Dyn. 2011, 38, 1421-1431.

36. Ogi, M.; Wallace, J.M. Summer minimum Arctic sea ice extent and the associated summer atmospheric circulation. Geophys. Res. Lett. 2007, doi: 10.1029/2007GL029897.

37. Walker, D.A.; Bhatt, U.S.; Epstein, H.E.; Bieniek, P.; Comiso, J.; Frost, G.V.; Pinzon, J.; Raynolds, M.K.; Tucker, C.J. Changing Arctic tundra vegetation biomass and Greenness. Bull. Am. Meteorol. Soc. 2012, 93, S138-S139.

38. Walker, D.A.; Epstein, H.E.; Raynolds, M.K.; Kuss, P.; Kopecky, M.A.; Frost, G.V.; Daniëls, F.J.A.; Leibman, M.O.; Moskalenko, N.G.; Matyshak, G.V.; et al. Environment, vegetation and greenness (NDVI) along the North America and Eurasia Arctic transects. Environ. Res. Lett. 2012, 7, 015504.

39. Comiso, J.C.; Nishio, F. Trends in the sea ice cover using enhanced and compatible AMSR-E, SSM/I, and SMMR data. J. Geophys. Res. 2008, doi: 10.1029/2007JC004257.

40. Comiso, J.C. Warming trends in the Arctic from clear sky satellite observations. J. Clim. 2003, $16,3498-3510$.

41. Global Inventory Modeling and Mapping Studies (GIMMS). Available online: http://gcmd.nasa.gov/records/GCMD_GLCF_GIMMS.html (Accessed on 18 August 2013). 
42. Huete, A.; Didan, K.; Miura, T.; Rodriguez, E.P.; Gao, X.; Ferreira, L.G. Overview of the radiometric and biophysical performance of the MODIS vegetation indices. Remote Sens. Environ. 2002, 83, 195-213.

43. Tucker, C.J.; Sellers, P.J. Satellite remote sensing of primary production. Int. J. Remote Sens. 1986, 7, 1395-1416.

44. Treshnikov, A.F. Atlas of the Arctic (in Russian); Treshnikov, A.F.E., Ed.; Administrator of Geodesy and Cartography of the Soviet Ministry: Moscow, Russia, 1985.

45. Mudelsee, M. Climate Time Series Analysis; Springer: Dordrecht, The Netherlands, 2010; Volume 42.

46. Mudelsee, M. Break function regression. Eur. Phys. J. Spec. Top. 2009, 174, 49-63.

47. Walker, D.A.; Bhatt, U.S.; Comiso, J.C.; Epstein, H.E.; Gould, W.A.; Henry, G.H.R.; Jia, G.J.; Kokelj, S.V.; Lantz, T.C.; Mercado-Díaz, J.A.; et al. Arctic: Land: Vegetation (in "State of the Climate in 2009"). Bull. Am. Meteorol. Soc. 2010, 91, S79-S82.

48. Matthewman, N.J.; Magnusdottir, G. Observed interaction between Pacific sea ice and the Western Pacific pattern on intraseasonal time scales. J. Clim. 2011, 24, 5031-5042.

49. Comiso, J.C. Large decadal decline of the Arctic multiyear ice cover. J. Clim. 2012, 25, 1176-1193.

50. Comiso, J.C. Polar Oceans from Space; Springer: New York, NY, USA, 2010; pp. 1-12.

51. Bulygina, O.N.; Razuvaev, V.N.; Korshunova, N.N. Changes in snow cover over Northern Eurasia in the last few decades. Environ. Res. Lett. 2009, 4, 045026.

52. Cohen, J.L.; Furtado, J.C.; Barlow, M.A.; Alexeev, V.A.; Cherry, J.E. Arctic warming, increasing snow cover and widespread boreal winter cooling. Environ. Res. Lett. 2012, 7, 014007.

53. Liu, J.; Curry, J.A.; Wang, H.; Song, M.; Horton, R.M. Impact of declining Arctic sea ice on winter snowfall. Proc. Natl. Acad. Sci. USA 2012, 109, 4074-4079.

54. Brown, R.D.; Derksen, C. Is Eurasian October snow cover extent increasing? Environ. Res. Lett. 2013, 8, 024006.

55. Polyakov, I.V.; Bhatt, U.S.; Walsh, J.E.; Abrahamsen, E.P. Recent oceanic changes in the Arctic in the context of longer term observations. Ecol. Appl. 2013, doi: 10.1890/11-0902.1.

56. Liu, Y.; Key, J.R.; Liu, Z.; Wang, X.; Vavrus, S.J. A cloudier Arctic expected with diminishing sea ice. Geophys. Res. Lett. 2012, doi: 10.1029/2012GL05125.

57. Comiso, J.C. Arctic warming signals from satellite observations. Weather 2006, 61, 70-76.

58. Tang, Q.; Leng, G. Damped summer warming accompanied with cloud cover increase over Eurasia from 1982 to 2009. Environ. Res. Lett. 2012, 7, 014004.

59. Bieniek, P.A. Assessing River Ice Breakup Date, Coastal Tundra Vegetation and Climate Divisions in the Context of Alaska Climate Variability; University of Alaska Fairbanks: Fairbanks, AK, USA, 2012.

60. Brown, R. Personal Communication, Montreal, QC, Canada, 2013.

61. Callaghan, T.V.; Johansson, M.; Brown, R.D.; Groisman, P.Y.; Labba, N.; Radionov, V.; Bradley, R.S.; Blangy, S.; Bulygina, O.N.; Christensen, T.R.; et al. Multiple effects of changes in Arctic snow cover. AMBIO 2012, 40, 32-45. 
62. Bhatt, U.S.; Walker, D.A.; Raynolds, M.A.; Epstein, H.E.; Pinzon, J.E.; Tucker, C.J.; Comiso, J.C.; Bieniek, P.A.; Mike, S. Seasonality of Arctic Tundra Greening. Earth Interact. 2010, unsubmitted.

63. Ogi, M.; Rigor, I.G. Trends in Arctic sea ice and the role of atmospheric circulation. Atmos. Sci. Lett. 2013, 14, 97-101.

64. Easterling, D.R.; Wehner, M.F. Is the climate warming or cooling? Geophys. Res. Lett. 2009, 36, L08706.

65. Meehl, G.A.; Arblaster, J.M.; Fasullo, J.T.; Hu, A.; Trenberth, K.E. Model-based evidence of deep-ocean heat uptake during surface-temperature hiatus periods. Nat. Clim. Chang. 2011, 1, $360-364$.

66. Pinzon, J. Personal Communication, Greenbelt, MD, USA, 2013.

67. Fensholt, R.; Proud, S.R. Evaluation of Earth Observation based global long term vegetation trends-Comparing GIMMS and MODIS global NDVI time series. Remote Sens. Environ. 2012, 119, 131-147.

68. Forkel, M.; Carvalhais, N.; Verbesselt, J.; Mahecha, M.; Neigh, C.; Reichstein, M. Trend change detection in NDVI time series: Effects of inter-annual variability and methodology. Remote Sens. 2013, 5, 2113-2144.

69. Jong, R.; Verbesselt, J.; Schaepman, M.E.; Bruin, S. Trend changes in global greening and browning: Contribution of short-term trends to longer-term change. Glob. Chang. Biol. 2011, 18, $642-655$.

70. Alexeev, V.A.; Langen, P.L.; Bates, J.R. Polar amplification of surface warming on an aquaplanet in "ghost forcing" experiments without sea ice feedbacks. Clim. Dyn. 2005, 24, 655-666.

71. Zhang, X.; He, J.; Zhang, J.; Polyakov, I.; Gerdes, R.; Inoue, J.; Wu, P. Enhanced poleward moisture transport and amplified northern high-latitude wetting trend. Nat. Clim. Chang. 2012, 3, 47-51.

72. Moore, G.W.K. Decadal variability and a recent amplification of the summer Beaufort Sea High. Geophys. Res. Lett. 2012, doi: 10.1029/2012GL051570.

73. Stegall, S.T.; Zhang, J. Wind field climatology, changes, and extremes in the Chukchi-Beaufort Seas and Alaska North Slope during 1979-2009. J. Clim. 2012, 25, 8075-8089.

74. Zhang, X.; Sorteberg, A.; Zhang, J.; Gerdes, R.; Comiso, J.C. Recent radical shifts of atmospheric circulations and rapid changes in Arctic climate system. Geophys. Res. Lett. 2008, 35, L22701.

75. Ogi, M.; Yamazaki, K. Trends in the summer Northern Annular Mode and Arctic sea ice. SOLA 2010, 6, 41-44.

76. Liu, L. Personal Communication, Madison, WI, USA, 2013.

77. NOAA/ESRL Physical Sciences Division, Boulder Colorado. Available online: http://www.esrl.noaa.gov/psd/ (accessed on 18 August 2013).

78. Urban, M.; Eberle, J.; Hüttich, C.; Schmullius, C.; Herold, M. Comparison of satellite-derived land surface temperature and air temperature from meteorological stations on the pan-Arctic Scale. Remote Sens. 2013, 5, 2348-2367. 


\section{Appendix}

Figure A1. Magnitude trends for land-surface summer warmth index (SWI) $\left({ }^{\circ} \mathrm{C}\right.$ month), based on (a) satellite data and (b) station data. The total trend magnitude (regression times 27 years) covers the 1982-2008 period. Larger circles in panel b indicate larger statistical significance than smaller circles.
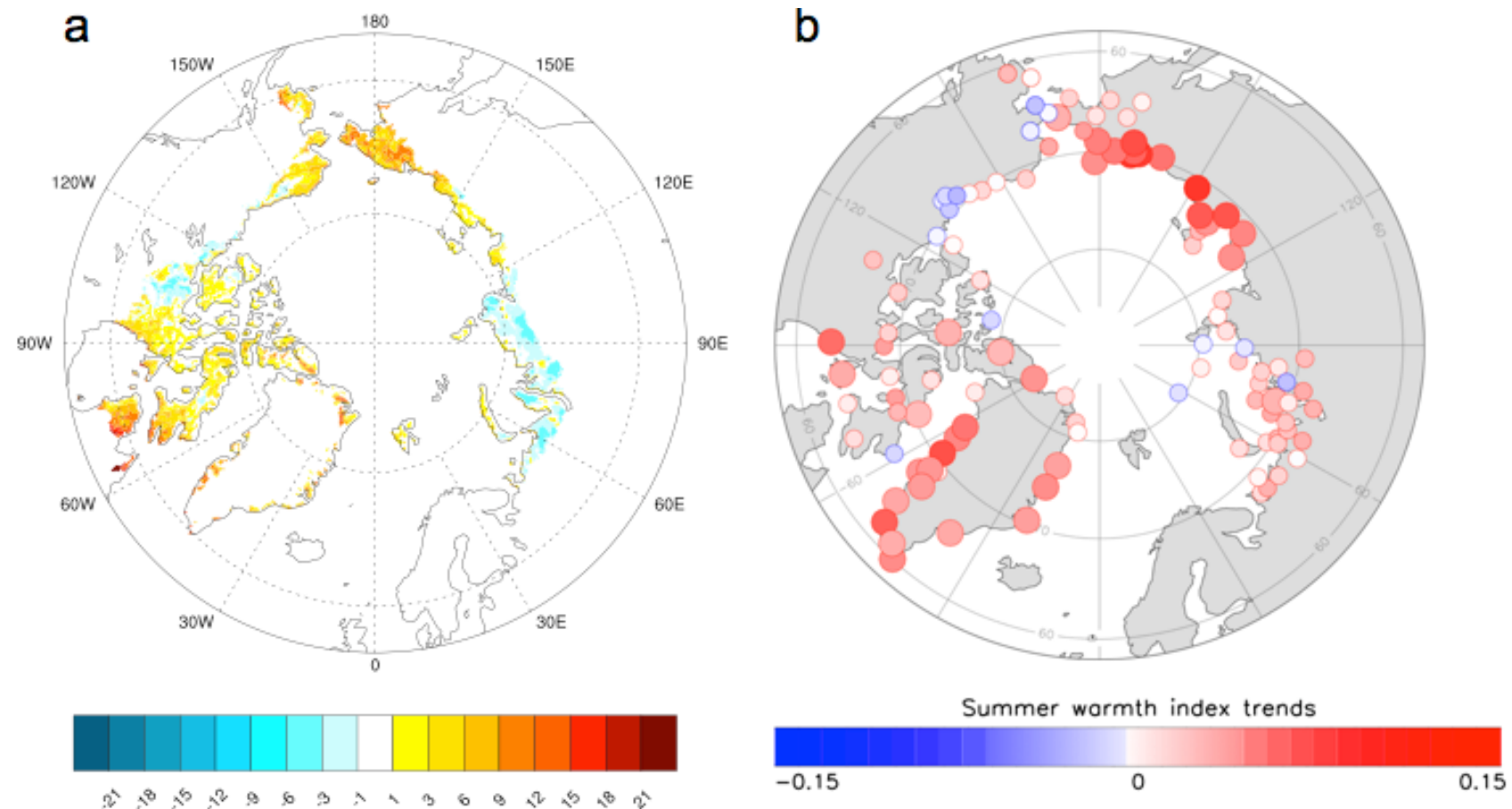

(C) 2013 by the authors; licensee MDPI, Basel, Switzerland. This article is an open access article distributed under the terms and conditions of the Creative Commons Attribution license (http://creativecommons.org/licenses/by/3.0/). 